\title{
استخدام الطريقة الإيحائية لترقية مهارة الاستماع في تعليم اللغة العربية
}

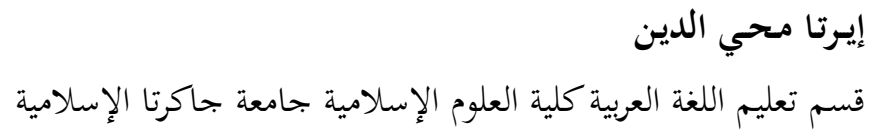

Email: ermahfir@gmail.com

\author{
حكمة \\ قسم تعليم العلوم الإسلامية جامعة نور الهداية الإسلامية رياوو \\ Email: jj0115420@gmail.com
}

\begin{abstract}
ملخص البحث
يهدف هذا البحث إلى الكشف عن فعالية الطريقة الإيحائية في تعليم مهارة الاستماع لطالبات مدرسة "الرحمة" المتوسطة للبنات بمالانج. ومن خلاله، يحاول هذا البحث للإجابة عن الأسئلة الآتية: (1) كيف كان يتم استخدام الطريقة الإيحائية في تعليم اللغة العربية لمهارة الاستماع ؟ (ז) إلى أي مدى فعالية استخدام الطريقة الإيحائية من ناحية

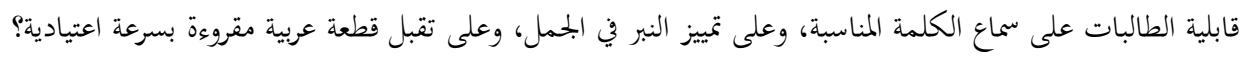

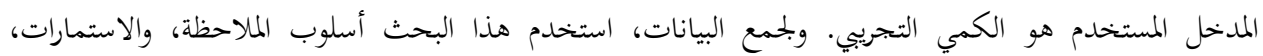

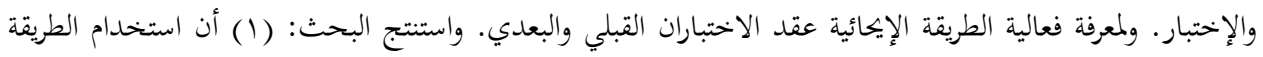

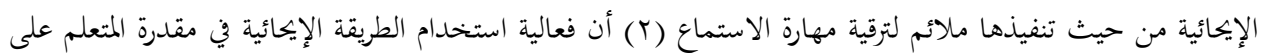

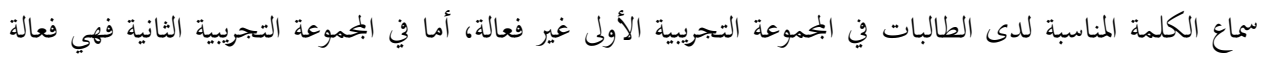

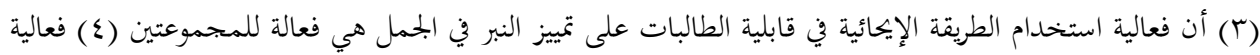
استخدام الطريقة الإيحائية في قدرة الطالبات على التعرف لقطعة عربية مسموعة بسرعة اعتيادية هي فعالة للمجموعتين. المصطلحات الرئيسية : الطريقة الإيحائية، مهارة الاستماع، فهم المسموع، النبر، فعالية، قابلية
\end{abstract}

\section{ABSTRACT}

This study aims to test the effectiveness of using suggestopedia method in teaching listening skills for students of Madrasah Al-Hikmah, Malang. The focus of this study was to answer some questions: 1) how is the application of suggestopedia method in listening; 2 ) how is the effectiveness of using suggestopedia method in listening, especially the ability to distinguish stressing an intonation and the ability to understand the Arabic language fragment of reading. It applied quantitative approach with an experimental design by comparing experimental and control class. To gain the data, It applied some techniques, including: observation, interview, 
إيرتا محي الدين, حكمة

doing test (pre and post), and questionnaire. Data collected were analyzed through the following steps: determining test for normality of data, determining test the homogeneity of data, analyzing of the pre-test results, analyzing post-test results, analyzing the results before and after treatment, and a comparing analysis on final results from experimental and control class. The findings show that: (a) The suggestopedia method is appropriate to upgrade students' skill in listening. (b) it boosts learners' ability in listening right word for for $2^{\text {nd }}$ eksperimental class is effective but it did not work for $1^{\text {st }}$ class experiment. (c) The impact of suggestopedia method to the students' ability in discerning word stressing in sentences for both experimental classes is effective. (d) The impact of suggestopedia method used to students' ability in recognizing script played on audio media in normal speed for both experimental classes is effective.

Keywords: Suggestopedia Method, Listening Comprehention, Stressing, Effectivity, Acceptance.

المقدمة

تعليم اللغة العربية يهدف إلى ترقية قدرة الطلبة في الاتصال باللغة العربية الصحيحة، تحريريا

وشفهيا. العديد من الطلبة يريدون أن يتقنوا هذه اللغة بجميع مهاراتا الأربع. والوصول إلى هذه القدرة يستلزم عدة لوازم الأمر منها في البداية القدرة على الاستماع دقيقا. فأصبحت مهارة الاستماع اليوم موضوعا يزداد مهما بسبب تزايد الاهتمام والتركيز على الاتصال المباشر في اللغات الأجنبية. وهو من إحدى المهارات في تعليم اللغة العربية ويكون أساسا مهما في فهم كالام الإنسان. فإن إهمال مهارة الاستماع يقود إلى عدم إتقان الكلام الجيد والقراءة الجيدة.

قد تعلم الطلاب الإندونيسيين مهارة الاستماع، ولكن في الواقع إن كثيرا منهم لم يفهموا ما يستمعون إليه جيدا، وإن حاولوا على الفهم أخطؤوا كثيرا. وذلك مثل ما يظهر لدى الطالبات في مدرسة "الرحمة" المتوسطة، إذن لا يفهمن مادة اللغة العربية إلا قليلا، هن غير ماهرات في سماع الكلمة، أو الجملة من النص المسموع، وغير قادرات على تمييز نبر الجمل، وغير قادرات على فهم نصوص عربية مقروءة بسرعة اعتيادية. شرحت إحدى الأستاذات في هذه المدرسة أن درجة استيعاب الطالبات على اللغة العربية وخاصة مهارة الاستماع فقط يبلغ ·ج في المائة (الملاحظة قي مدرسة "الرحمة" المتوسطة

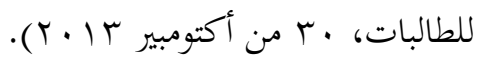

تعليم الاستماع في تعليم اللغة العربية يواجه إشكالية كثيرة اتضحت من ضعف فهم الطلاب عندما يستمعون إلى المادة المسموعة. من المشاكل في تعليم الاستماع مما يلي: (1) قلة الكتاب الأساسي للمعلم، (Y) قلة الخبرة لدى المعلم في تعليم الاستماع، (r) قلة الكتاب المدرسي لتعليم 
الاستماع، (ع) قلة الإختراف عند المعلم في كتابة مفردات تعليم الاستماع، و(0) عدد الطلاب كبير.

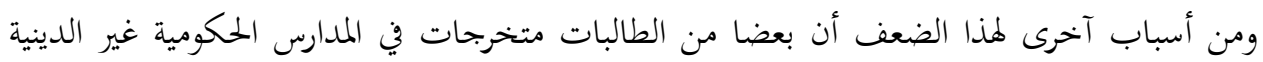
التى لا يقدم فيه درس اللغة العربية كمادة مدروسة. فأصبحت اللغة العربية في المرحلة المتوسطة جديدة المديدة

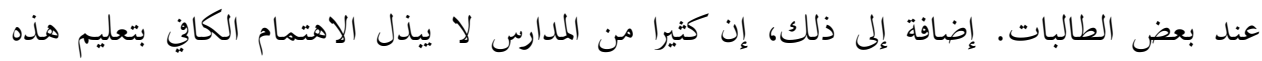
المهارة، وكذلك المعلم استخدم الطريقة غير المناسبة، ونتيجة ذلك تشعر الطالبات بالملل في ألمدار أثناء

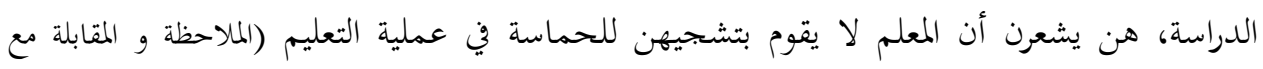

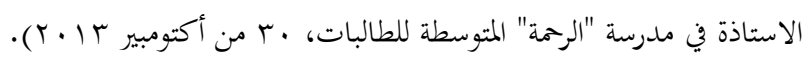

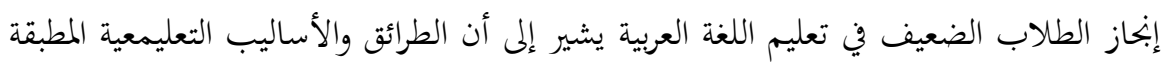

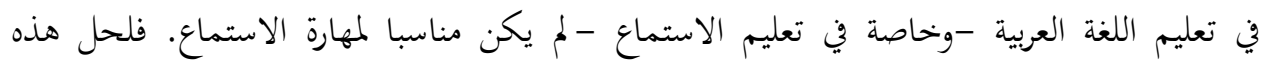

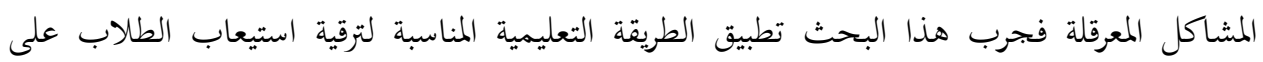
الاستماع. وهذه الطريقة هي المسماة بمنهج أو بطريقة إيحائية كuggestopedia Method.

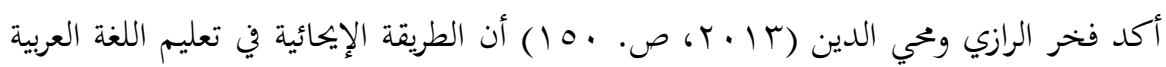

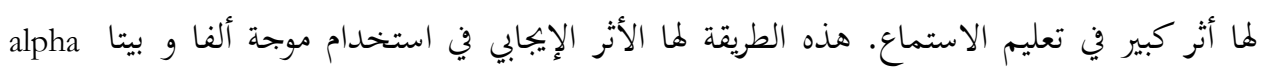
betha

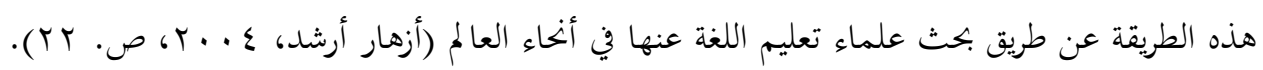

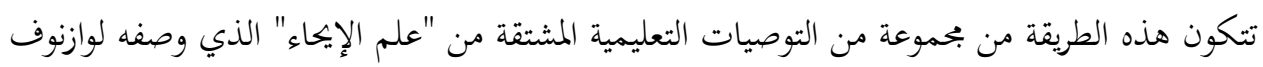

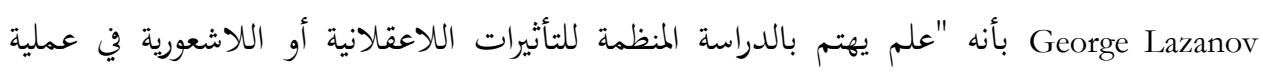

$$
\text { التعليم (جاك رتشاردز، . 199، ص (TVO). }
$$

ينظر إلى هذا المنهج التعليمي باعتباره أكثر المداخل غرابة في إطار مايسمى بـ (المداخل

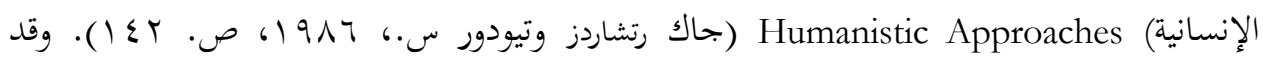

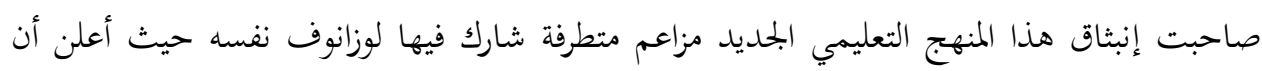

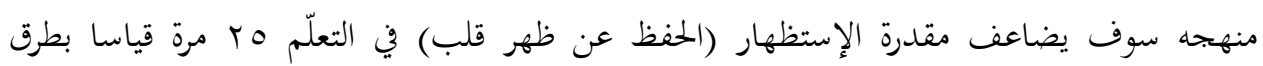

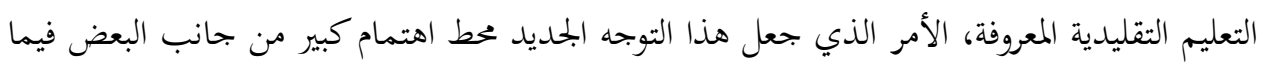

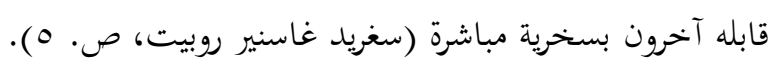

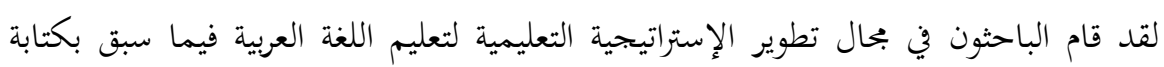

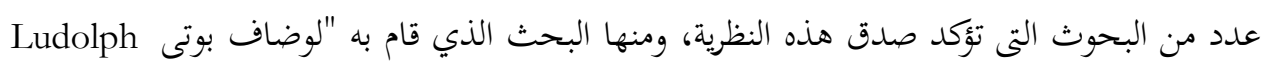


إيرتا محي الدين, حكمة

Botha الطريقة الإيحائية أكثر فعالة لدى الطلبة. إن الطلبة مقتنعين و راضين بمعلمهم أكثر من الطرق التعليمية الأخرى. وفي نفس السياق، قام Sigrid Gassner-Roberts بالبحث تحت العنوان "بعض ملاحظات فردية حول الطريقة الإيحائية في يابان و أوربا". واستخلص الباحث أن الطريقة الإيحائية ناجحة في تعليم اللغة. وقام الباحث الآخر -دؤي رسماينتي سومنتري- بالبحث لمعرفة فعالية الطريقة الإيحائية استناد

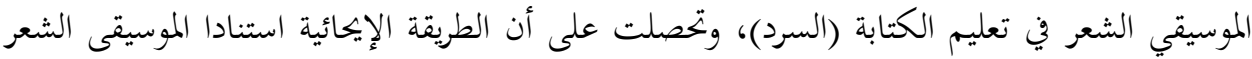

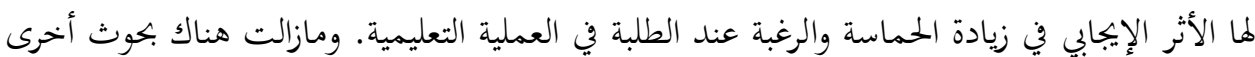
تتكلم عن الطريقة الإيمائية ولكنها لم تدخل في موضوع الاستعاع في تعليم اللغة العربية. فبناء على هذه الخلفية، يهدف هذا البحث إلى الكشف عن فعالية الطريقة الإيحائية في تعليم مهارة الاستماع. وجرى هذا البحث في مدرسة "الرحمة" المتوسطة للبنات بمالانج جاوى الشرقية". ومن خلاله، يماول هذا البحث للإجابة عن الأسئلة الآتية: أولا: كيف يتم استخدام الطريقة الإيحائية في تعليم اللغة العربية لمهارة الاستماع في مدرسة "الرحمة" المتوسطة للبنات بمالانج جاوى الشرقية؟ وثانيا: إلى أي مدى فعالية استخدام الطريقة الإيحائية من ناحية قابلية الطالبات على سماع الكلمة المناسبة؛ وعلى تمييز النبر في الجمل، وعلى تقبل قطعة عربية مقروءة بسرعة اعتيادية ؟ يستخدم هذا البحث المدخل الكمي، لأنه يعتمد في بحثه على الأعداد عند تحليل البيانات المكتشفة وعند استخلاص نتائج البحث. ونوع المنهج الكمي المتبع في هذا البحث هو المنهج التجريبي. ونوع الطريقة المستخدمة في هذا البحث هي منهج البحث عن طريق شبه بحربة ( .(Experiment المجتمع المدروس في هذا البحث هو طالبات مدرسة "الرحمة" المتوسطة للبنات بمالانج للعام

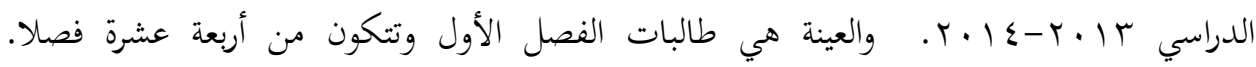
واستخدم البحث طريفة عينة عنقودية عشوائية في أخذ عينات البحث التى تنقسم إلى قسمين: المجموعة

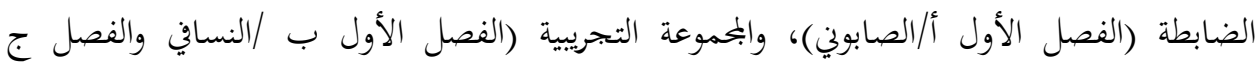

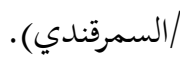

وللحصول على المعلومات أو البيانات المهادوفة المساعدة في إجابة أسئلة البحث، يعتمد هذا البحث على وسائل وأدوات البحث التالية: (1) الملاحظة: في مدرسة "الرحمة" المتوسطة المرحلة الأول. واستخدم البحث الملاحظة المباشرة وغير المباشرة. استخدمت كلاهما للحصول على البيانات لمعرفة 
فعالية الطريقة الإيحائية بنظر إلى أحوال الطالبات عند عملية التعليم باستخدام هذه الطريقة. (r)

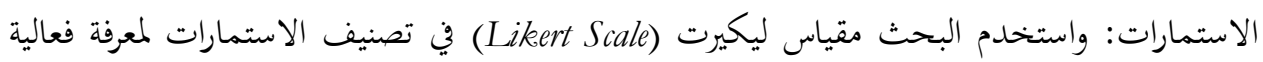

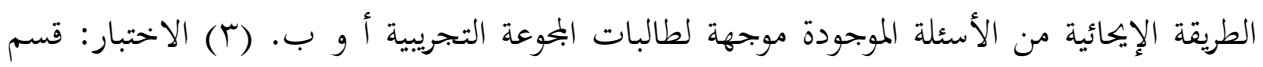
الاختبار إلى نوعين، هما الاختبار القبلي والاختبار البعدي.

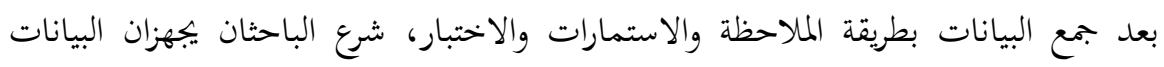
ويعداغا لغاية التحصيل الإحصائي والوصول إلى نتائج البحث. ولتحليل اختبار الفرضية قام الباحثان

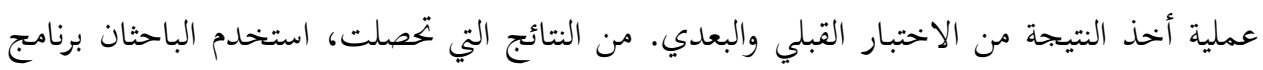

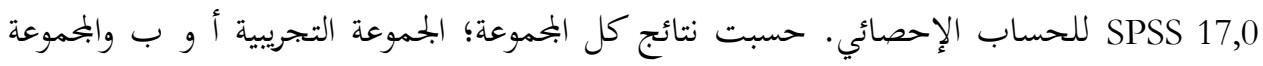

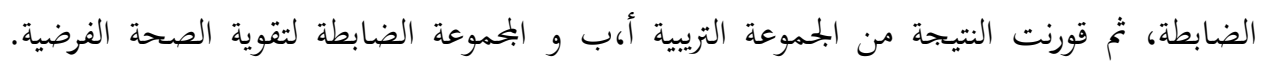

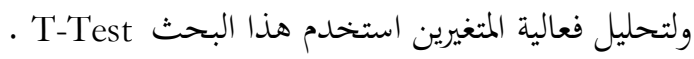

\section{البحث \\ تعليم الإستماع}

تتضمن عملية الاتصال جانبي الإرسال والاستقبال، ويتضمن جانب الإرسال في عملية

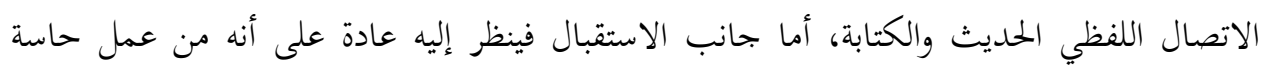

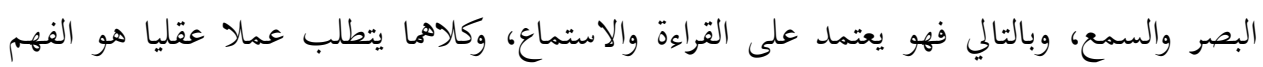

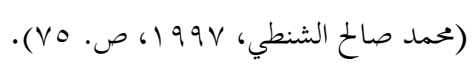

الاستماع هو فهم الكلام، أو الانتباه إلى شيء مسموع مثل الاستماع إلى متحدث، بخلاف

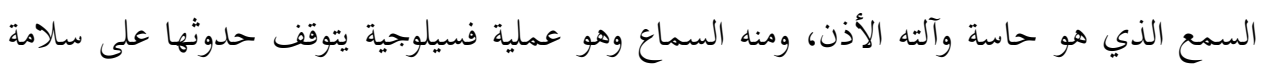

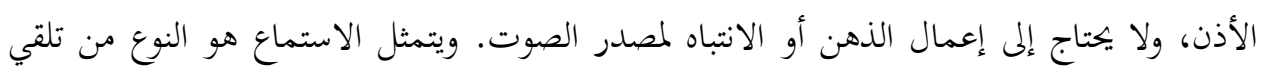

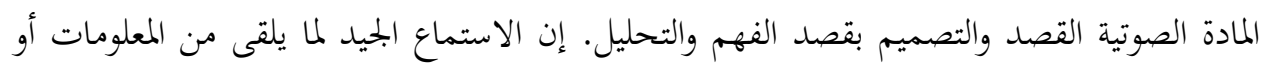

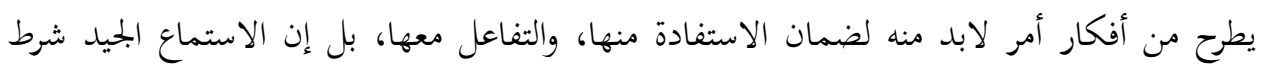

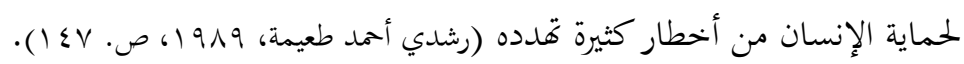

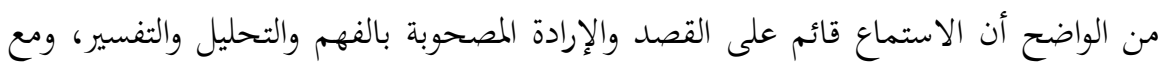

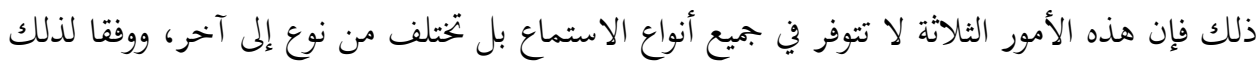

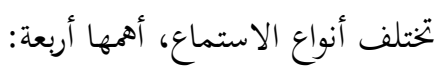


إيرتا محي الدين, حكمة

1- الاستماع الهامشي، وهو الذي يمارسه العامة عند إصغائهم لوسائل الاعلام المرئية والمسموعة،

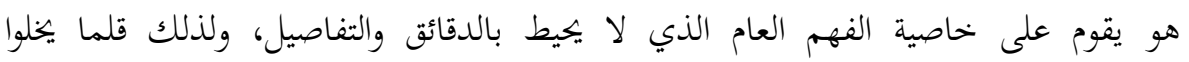
الاستعاب من خطأ أو تحريف، مثله في ذلك مثل استماع الناس لبعضهم البعض في الأحاديث العامة.

r- الاستماع الاستمثاعي، وهو ما يمارسه المرء حين يقصد إلى المتعة الروحية أو النفسية، كالاستماع

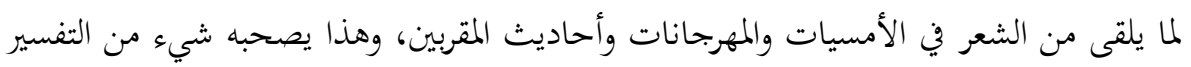
والتحليل والتذوق وليس من شك أن التذوق هو العنصر الغالب على هذا النوع من الاستماع.

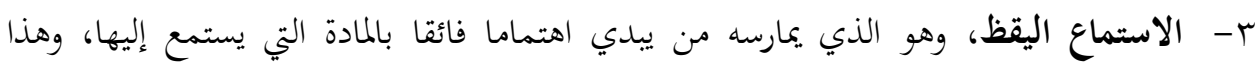
يتطلب نصيبا وافرا من الفهم المصحوب بالتفسير والتحليل.

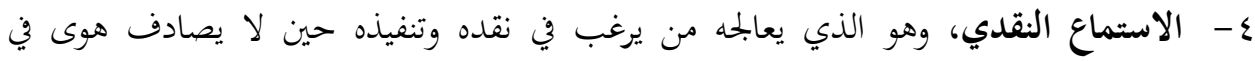

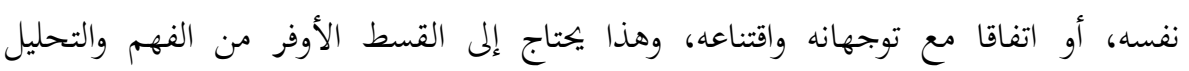

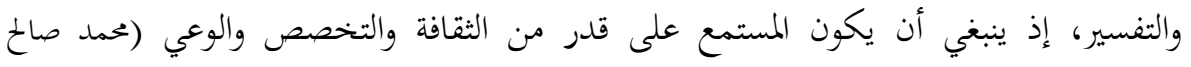

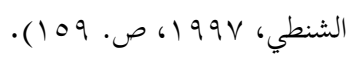

و هناك عدد من الأساليب التي تفيد في تدريب التلاميذ في الاستماع، وهي أساليب وظيفية

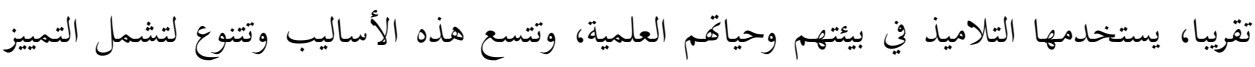

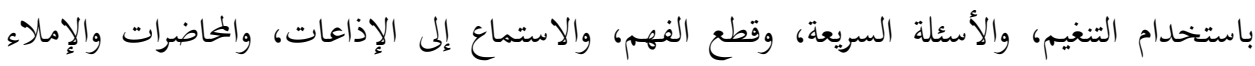

$$
\text { (حسان شحاته، 1999، ص. (17). }
$$

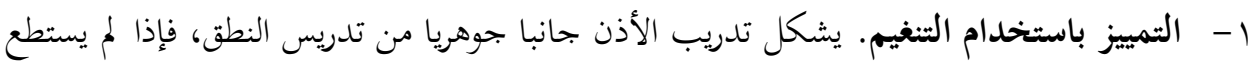

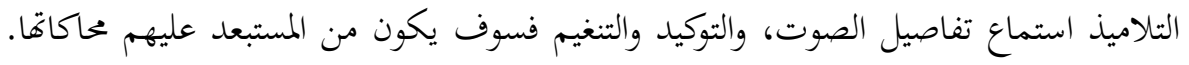

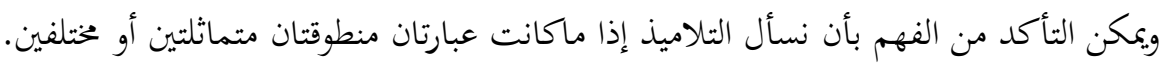

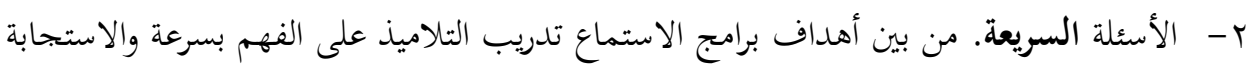

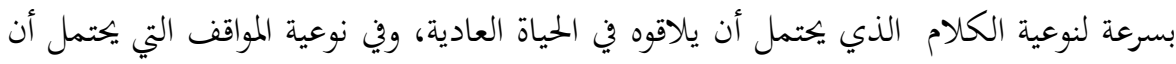

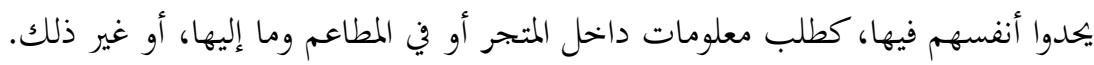

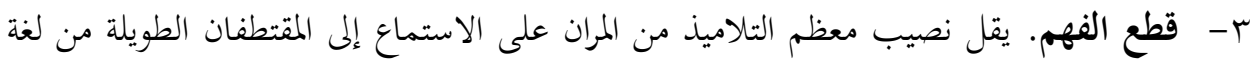

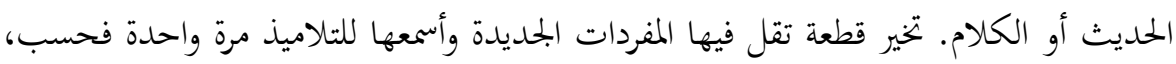
بذلك إعطاء التلاميذ مرانا على إدراك معنى اللغة المألوفة، والتي تلقى بسرعة وبشكل طبل فيبعي. 
ع - الإذاعات. من عناصر تعلم اللغة اكتساب القدرة على الاستماع للإذاعة بالراديوا، وهي هامة بالنسبة لأمور الحياة اليومية مثل الأخبار، أو التوقعات الجوية. كذلك بنسبة للأحاديث المتخصصة التي قد لا بحدها في مكان آخر، مثل المناقشات الثقافية، أو الاقتصادية، أو الأدبية.

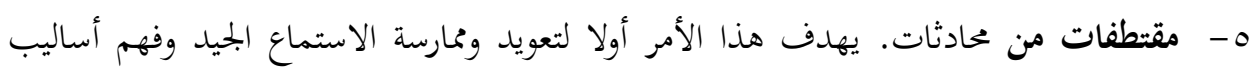
المحادثة، وثانيا لتشجيع التخمين، وعلى المستمع أن يحتفظ في ذهنه بمؤشرات لكي يكون على أساسها فروضا ثم يقوم بتحقيقها. 7 - المحاضرات. عادة هذه المحاضرات تكون في المرحلة المتوسطة وما بعدها إذاكانت تدرب الطلبة على الاستماع، والحفظ التلخيص، وتوجيه الأسئلة أو الإجابة عنها أمام جمهور، وأخذ المذكرات.

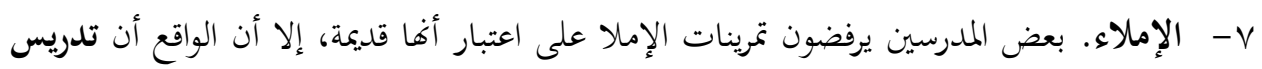
اللغة يجب أن يجمع بين أحسن ما في الأساليب القديمة، وتطبيق هذه الأساليب بطريقة معاصرة

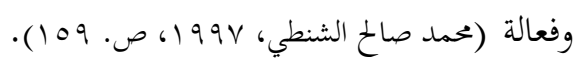

\section{الطريقة الإيحائية}

George الطريقة الإيحائية هي طريقة طورها الطبيب النفسي والمربى البحري جورجي لوزانوف لهن

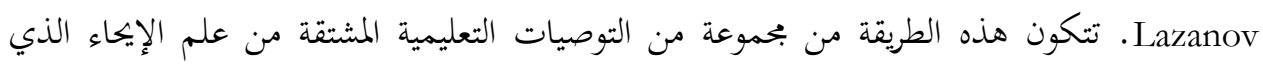
وصفه لوزانوف بأنه علم يهتم بالدراسة المنظمة للتأثيرات اللاعقلانية أو اللاشعورية التي يستجيب لما

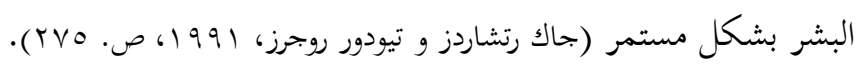

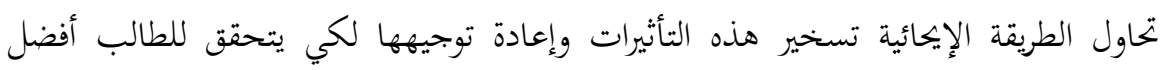
مستوى من التعلم. إن أبرز سمات هذه الطريقة هو استخدام الديكور، والأثاث، والطريقة الخاصة لترتيب غرفة الدراسة، واستعمال الموسيقي والسلوك السلطوي الذي يتبعه المعلم أثناء التدريس (عزيز

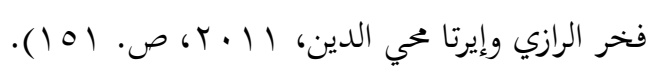

لم يفصح لوزانزف بوصفه للطريقة الإيحائية عن وجود نظرية لغة ولا هو أيضا، فيما يبدو، منهم

بأي افتراضات معينة بالنسبة لعناصر اللغة وتنظيمها. ولكن تأكيده على استظهار أزواج من الكلمات

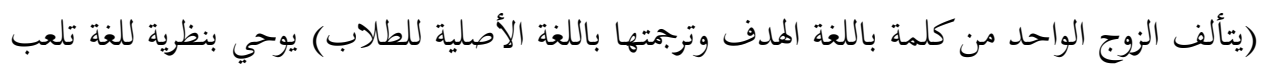
فيها الكلمات دورا مركزيا، ويؤكد فيها على ترجمة الكلمات وليس على معانيها في السياق الذي ترد فيه

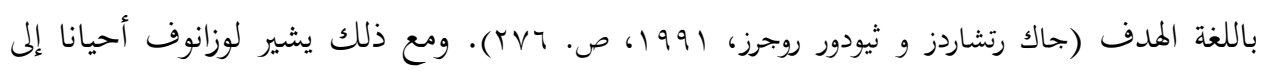




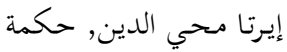

أهمية تقديم المادة اللغوية في (سياق شامل ذي معنى). ويذكر لوزانوف أن برنامج الطريقة الإيحائية لا يوجه الطالب إلى استظهار المفردات واكتساب عادة الكلام ولكن إلى ممارسات اتصالية. إن الإيحاء هو صميم الطريقة الإيمائية. فعند كثير من الناس، يعني الإيهاء نظرات التحديق

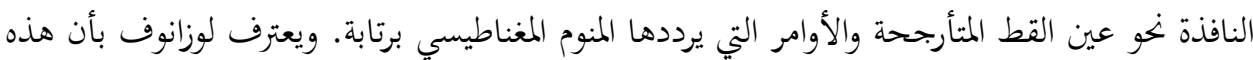

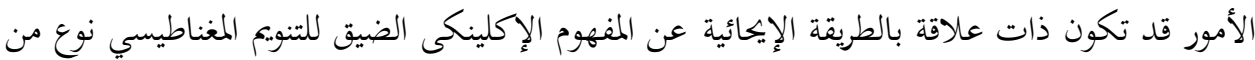

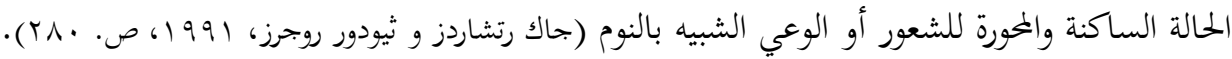

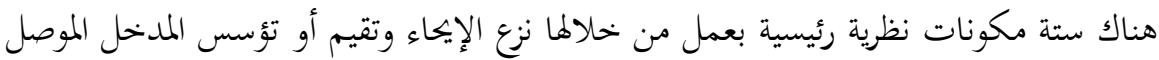

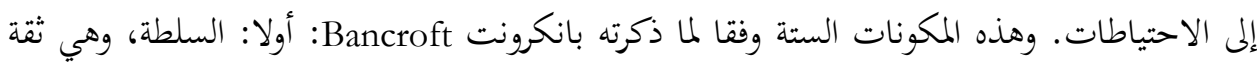
الطلبة بمعلمهم عند عملية التعليم و ثقة الطلبة في نفوسهم self confidence ثقة كبيرة حتى يشعر بأن له قدرة في التعليم. ثانيا: الطفلانية، وهي العلاقة بين المعلم و الطلبة مثل العلاقة بين الولدين والطفل، لفائه لذلك بند الدارس في الطريقة الإيحائية من خلال دور الطفل الذي يقوم به، يشترك في تمثيل الأدوار،

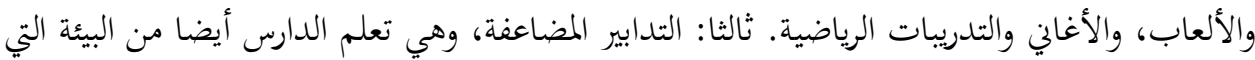

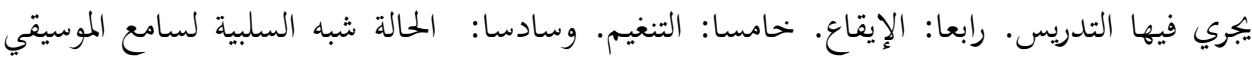

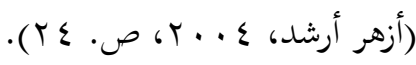
تمدف الطريقة الإيحائية إلى إعطاء الطلاب، وبسرعة، متقدمة في المحادثة. ويتضح لنا أن أسلوب هذه الطريقة يعتمد على إتقان الطلاب لقوائم ضخمة من أزواج من المفردات وكذلك على إلى إلى

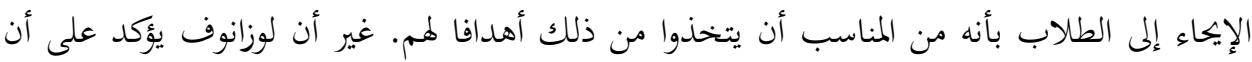
ازدياد قوة الذاكرة ليس مهارة منفصلة ولكنه نتيجة لإشارة إيهابية شاملة للشخصية (عزيز فخر الرازي

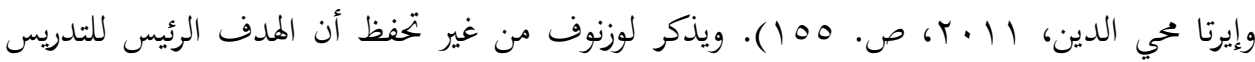
بالطريقة الإيحائية ليس الاستظهار ولكنه الفهم والحلول الإبداعية للمشكلات (جاك رتهات رتشاردز و ثيودور روجرز، 1991، ص. 1/10). ويذكر لوزنوف ازدياد تحقيق الفهم والحلول الابتكارية للمشكلات أهدافا

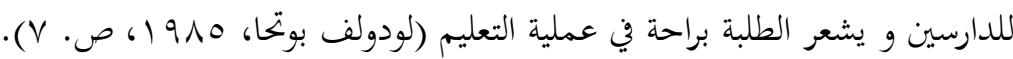

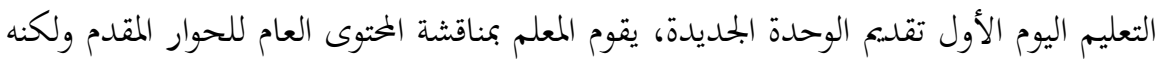

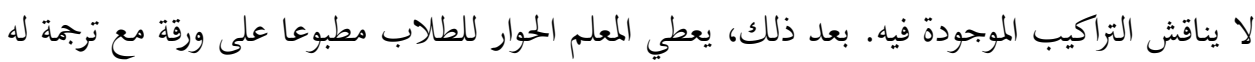

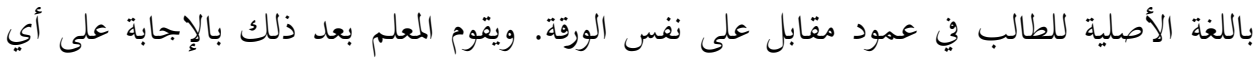


سؤال له أهمية أو علاقة بالحوار. ثم يقرأ المعلم الحوار مرة ثانية وثالثة (جاك رتشاردز و تيودور روجرز، .(Y人T.

هذا هو برنامج العمل في العمل الأول من الوحدة الدراسية. أما اليومان الثاني والثالث فيقضيان

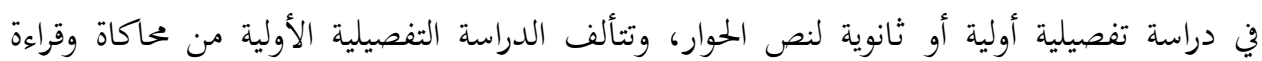

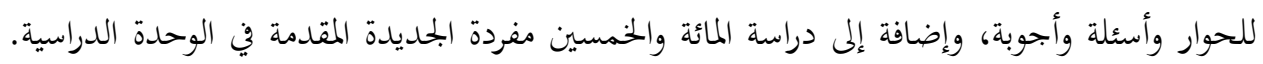

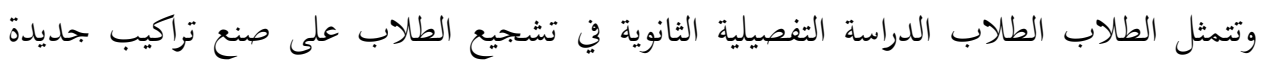

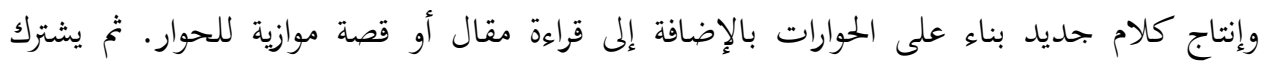

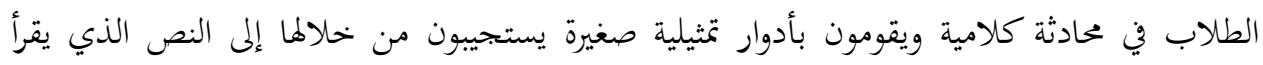

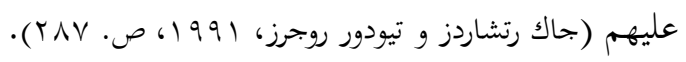

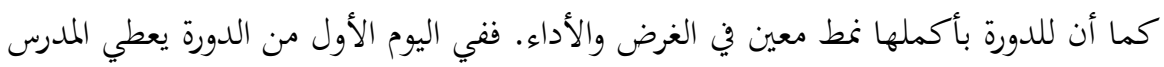
اختبارا لقياس مستوى معرفة الطلاب ولتقسيمهم إلى فريقين. فريق يتكون من الطلاب المبتدئين الجلدد،

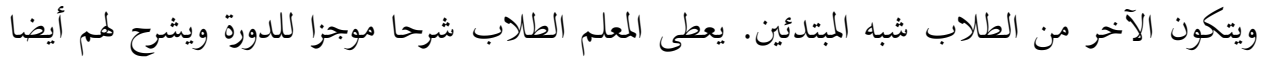

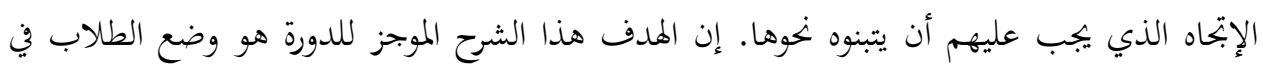

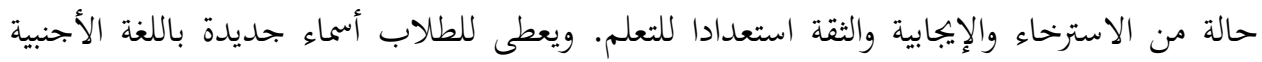

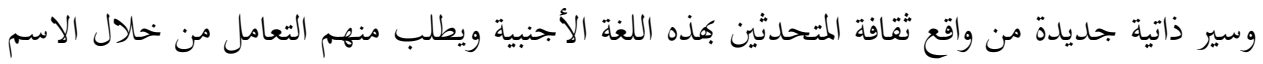
والسيرة الجديدين طوال مدة الدورة.

يمنح الطلاب خلال الدورة فرصتين لتعليم تعلم مهارة اللغوية. ففي منتصف الدورة يشجع الدورة

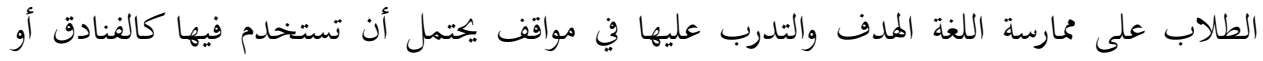

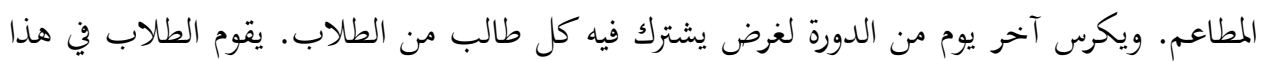

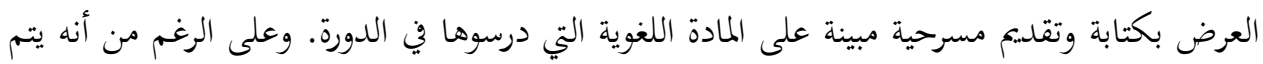

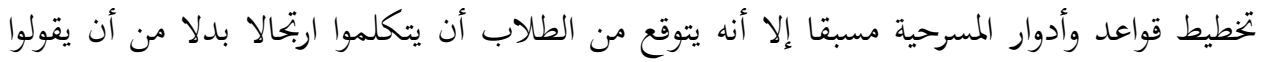

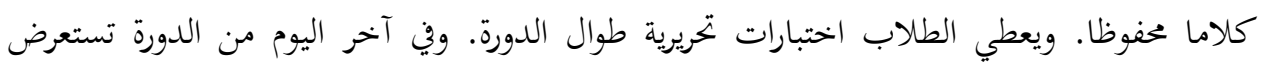

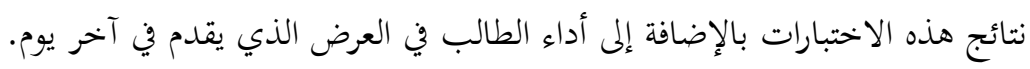

\section{إجراء الطريقة الإيحائية في تعليم مهارة الاستماع}

إن الأنشطة التي تتميز بها الطريقة الإيكئية عن الطرائق الأخرى لتعلم اللغة هي أنشطة

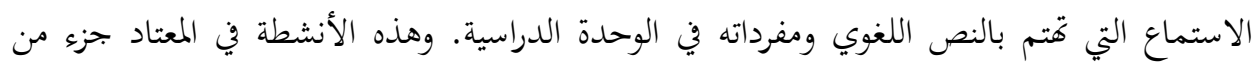




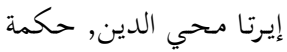

مرحلة قبل الدرس التي تتم في اليوم الأول من تدريس وحدة جديدة. يقوم الطلاب أولا في هذه

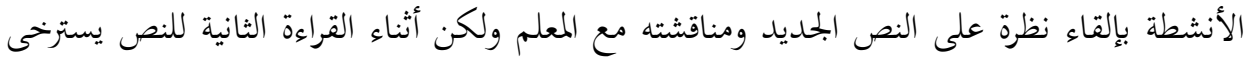

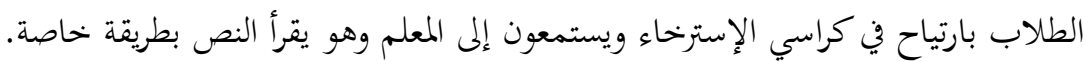

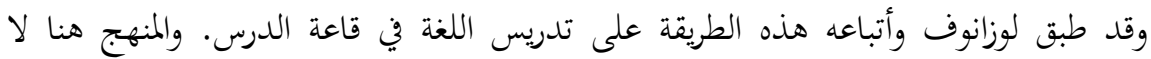

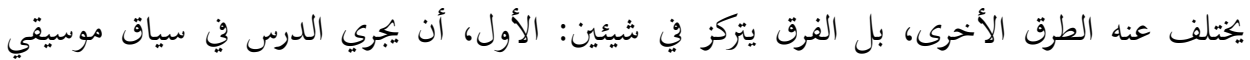

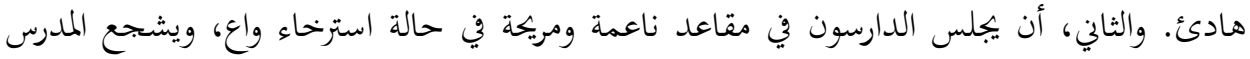

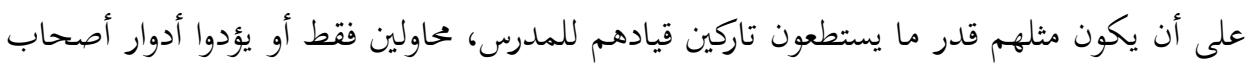

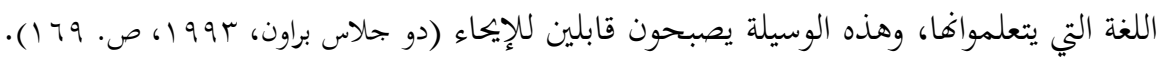

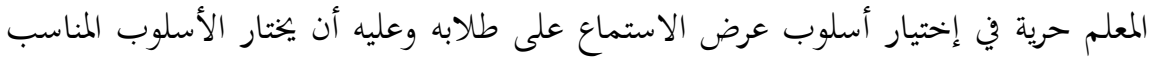

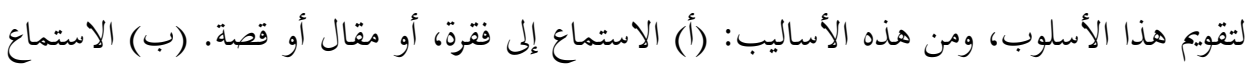

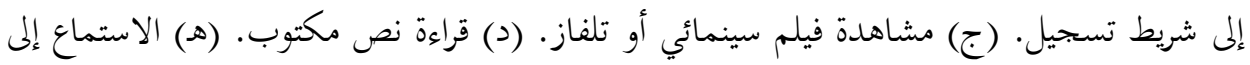

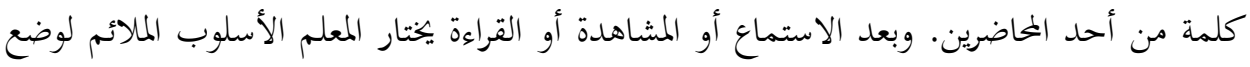

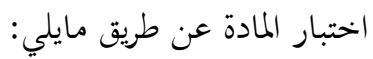

() أسئلة توجه إلى الطالب كتابية أو شفهية يجيب عنها شفاهيا أو كتابيا.

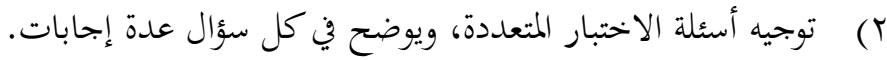
r) أسئلة الصواب والخطاء وفقا للنص الذي استمعه الطلبة.

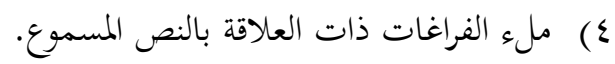
0) المزاوجة بين قائمتين في ضوء ما استمعه.

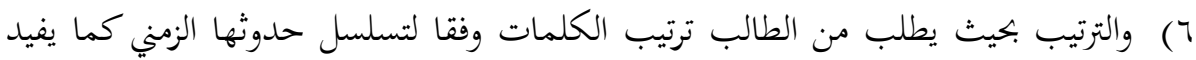

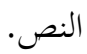
V التخيص كأن يلخص الطالب ما فهم من النص المسموع.

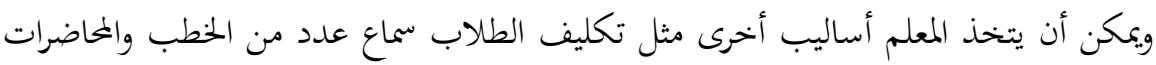
والندوات وتلخيصها أو عن طريق تطبيق البرنامج الاتصالي، أو عن طريق الحوارات والأسئلة التي يلقيها

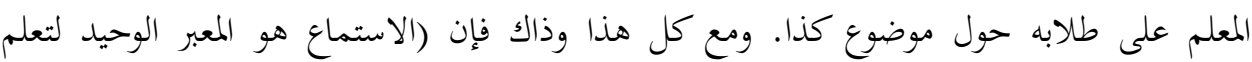
المهارات الأخرى: القراءة والحديث والكتابة وهو جزء من فنون اللغة ولهذا اهتم به التربويون واللغويون 
وأولوه عناية بالغة). فلابد من إظهار أهمية الاستماع في الحياة بصفة عامة وفي الحياة التعليمية بصفة خاصة، وإعداد البرامج التعليمية النافعة المثيلة والمناسبة للمستويات الدراسية.

\section{إجراء العملية التعليمية التجريبية}

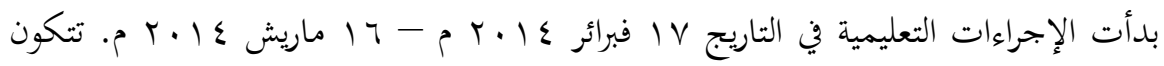
ثلاثة فصول؛ فصلان بتريبان و فصل ضابط واحد. ولكل فصل أربعة لقاءات. قبل بدأ التعليم باستخدام الطريقة الإيحائية قام الباحثان باختبار قبلي لمعرفة قدرة الطالبات في مادة اللغة العربية لمهارة الاستماع، خاصة في قياس قابلية سماع الكلمة المناسبة، قياس قابلية تمييز النبر في الجمل وقياس تقبل قطعة عربية مقروءة بسرعة إعتيادية. في اللقاء الأول عند التعليم باستخدام الطريقة الإيحائية أعد الباحثان الإعداد الكافي قبل دخول الفصل لأن هذه الطريقة المستخدمة تشترط أن يكون الفصل مريحا ونعيما. فأمر المدرسة الباحثة الطالبات قبل بداية الدراسة أن تحذف الكراسي في الفصل وتنظفها حتى يكون الفصل نظيفا، وألصق المدرسة المزينة في الجدار عن موضوع التعليم حتى أن تتكيف الطالبات جوا عربيا حقيقيا. بعد دخول الباحثة الفصل بدأتما بالسّام وسألت عن أحوال الطالبات، وبيّنت الباحثة عن الإجراءات التعليمية باستخدام الطريقة الإيحائية وسألت عن مشاكلهن في مادة اللغة العربية خاصة في تعليم مهارة الاستماع، وقدمت الباحثة الطرق لحل المشاكل الموجودة. وبعدها قامت بالاسترخاء وتقديم الإيحاء الجيد لهن مع تشغيل الموسيقى الهادئة، وأمرهن أن يغلقن أعينهن في لحظة حتى يشعرن بالإطمئنان واستعددن للتعلم استعداد جيدا وحماسة لأن شعور بالإطمئنان من إحدى خطوات الطريقة الإيحائية. ثم قسمت الباحثة الطالبات إلى خمس فروق، وجلسن بشكل دائر، وقرأت الحوار تحت الموضوع "المسجد" للطالبات، ثم وزّعت القراطيس فيها نص الحوار الذي لابد على الطالبات من أن فئن يجرين الحوار بطريقة المسرحية.

بعد قيام الطالبات بالحوار سألت الباحثة الطالبات أسئلة الاستيعاب حتى تفهم الطالبات نص الحوار فهما عميقا. والأنشطة بعدها هي اللعب لترقية مهارة الطالبات في الاستماع، اللعبة التي جرت هي "الهمس". جرت الطالبات اللعبة متحمسات وفرحات وقالت إحدى الطالبات أن اللعبة زادت حماستهن عند التعليم ولم يشعرن بالملل. وبعد انتهاء اللعبة، قدمت الباحثة الخلاصة من المادة التي تمت دراستها، وترجو الباحثة أن يكون ما قامت به لها منافع في العملية التعليمية وزادت العلوم خاصة في 
إيرتا محي الدين, حكمة

مادة اللغة العربية، ثم شرحت الباحثة الواجب المنزلي للطالبات، وهي أن تقرأن الحوار قبل النوم وبعد القيام منه. واختتمت الباحثة العملية التعليمية بالسّلام.

في اللقاء الثاني تمت الإجراءات التعليمية بنفس الأسلوب للذي جرى في اللقاء الأول، ولكن موضوع الحوار مختلف، في اللقاء الثاني جرى الحوار تحت الموضوع "الملعب والمطعم". وأما في اللقاء الثالث جرى العمل التعليمي عن طريق مشاهدة الفيلم تحت الموضوع "بر الوالدين". وفي اللقاء الرابع، جرى التعليم عن طريقة المسرحية تحت الموضوع "المقصف". في كل لقاء جاءت الأنشطة المختلفة، منها: المسرحية، اللعبة، المسابقة، وفهم المسموع من موسيق العربي. إن الطالبات يشعرن بالحماسة عند إجراء التعليم. صرحت إحدى الطالبات بأها كانت قبل ذلك لا تحب مادة اللغة العربية، لأهما مادة صعبة ومملة، ولكن بعد أن جرى التعليم بالطريقة الإيحائية صارت لها حماسة عند الذهاب إلى الفصل لتعلم وقالت بأن مادة اللغة العربية سهلة و مريحة. وهذه هي صورة تخطيط الخطوات التعليمية لكل لقاء:

\section{اللقاء الأول، الموضوع: المسجد}

1- الهدف العام : التعرف على الصوتين وتمييز بينهما باختلافاتما عند الاستخدام في الحديث r- الهدف الخاص: (1) أن يألف الدارس الأصوات العربية و أن يتعرف عليها سماعا و أن يميز بينهما (أصوات الحروف الموجودة في الحوار عن "المسجد"). (r) أن يختار الدارسون أنسب إجابة

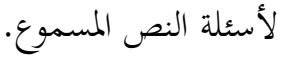

(ب) الجدول)

\begin{tabular}{|c|c|}
\hline \multicolumn{2}{|c|}{ تخطيط عام لعملية التدريس } \\
\hline الطالبات & المعلم \\
\hline تجيب الطالبات سؤال المعلمات الطالبات & • • • • • • • • • \\
\hline تقتري عملية الطالبات علىخاء الموسيقى وتدبر الإيحاء من المعلمة & 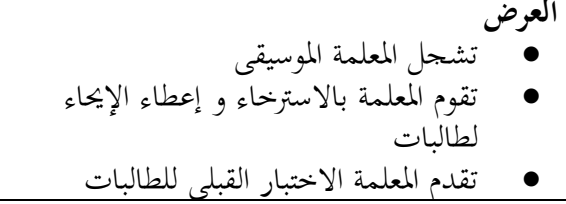 \\
\hline
\end{tabular}




\begin{tabular}{|c|c|}
\hline 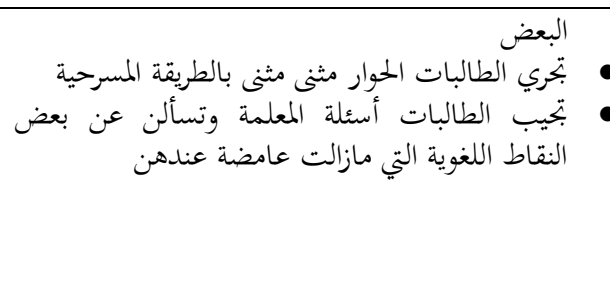 & 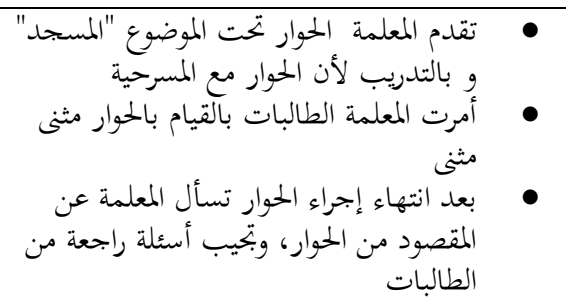 \\
\hline 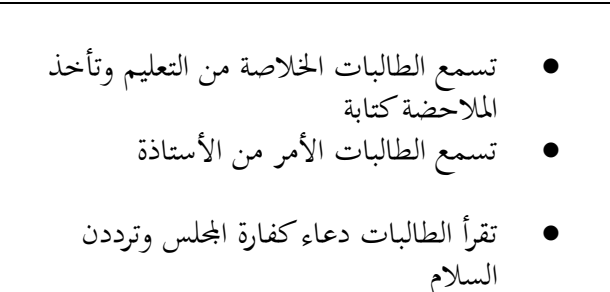 & 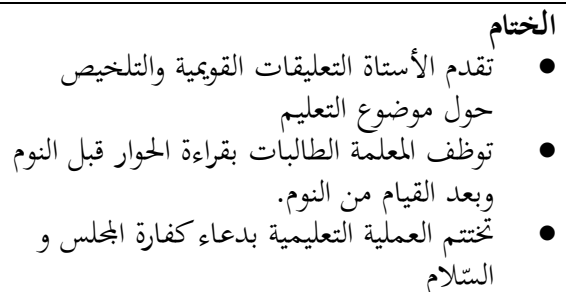 \\
\hline
\end{tabular}

اللقاء الثاني، الموضوع : الملعب والمطعم ا - الأهداف العام: (أ) التعرف على الأصوات العربية وتمييزها من الاختلافات ذاتعات ذات دلالة والمتشابهة

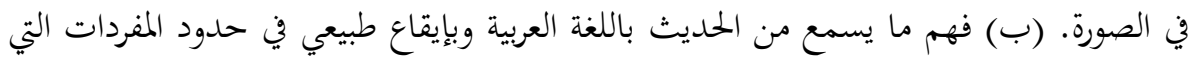
تم تعلمها ب- الأهداف الخاصة: (أ) أن يفرق الدارسون صوت الأحرف الهجائية (أو ع، ت و ط، ح و هـ،

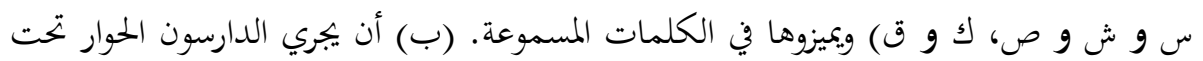

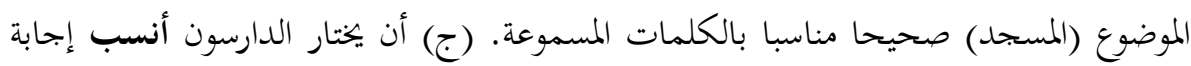

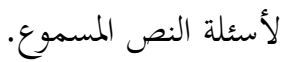

(飞) الجدول

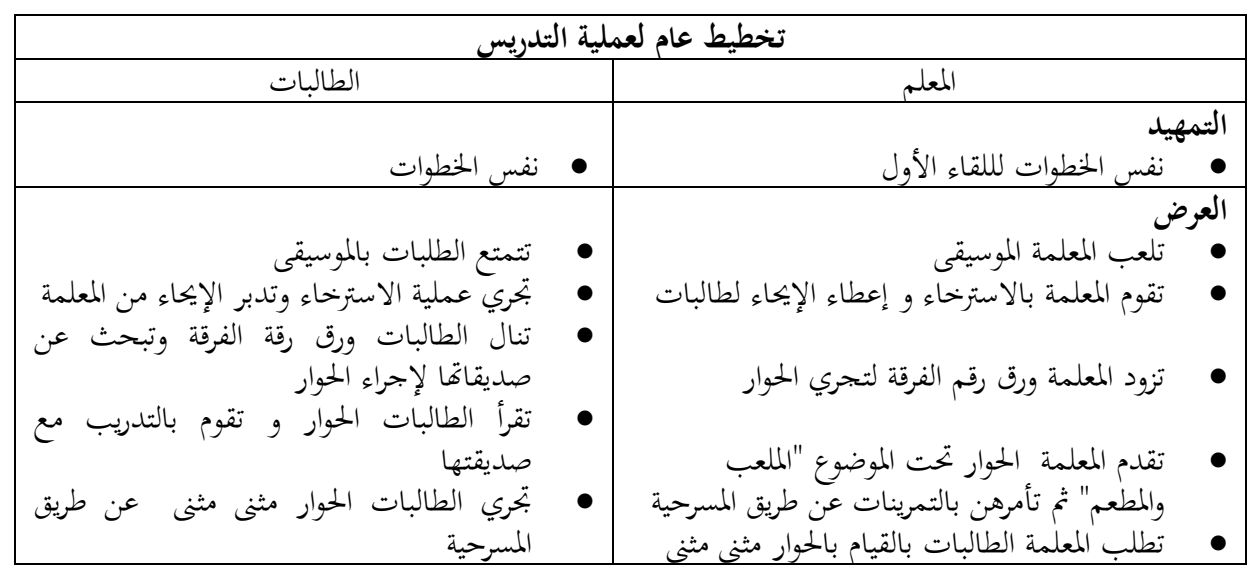


إيرتا محي الدين, حكمة

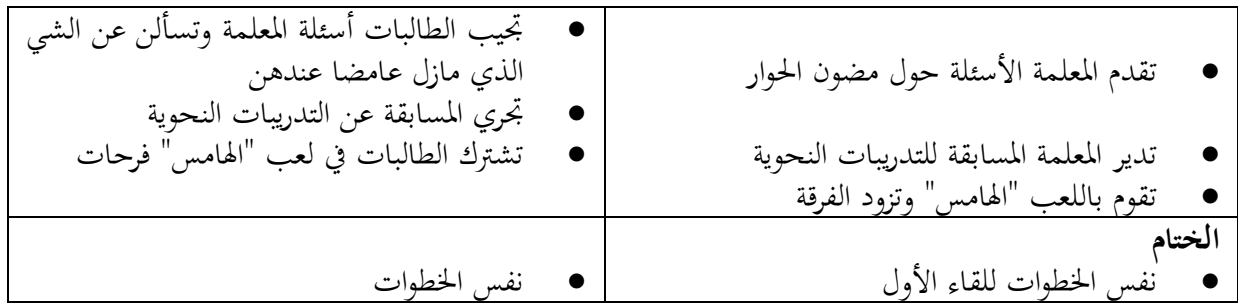

اللقاء الثالث، الموضوع: بر الوالدين

1- الهدف العام: فهم المعنى الإجمالي لسياقات النص المسموع المتوسط الطول عند نطقها أهل اللغة

بالسرعة العادية.

r - الأهداف الخاصة: (أ) أن يستخدم الدارس التعبيرات اليومية وعبارات التحية والمحاملة. (ب) أن يدرك الأصوات التي تنطق وليس لها رموز كتابية، والرموز التي تكتب وليس لها أصوات خاصة عند النطق مثل الألف والواو والياء

الجدول (•)

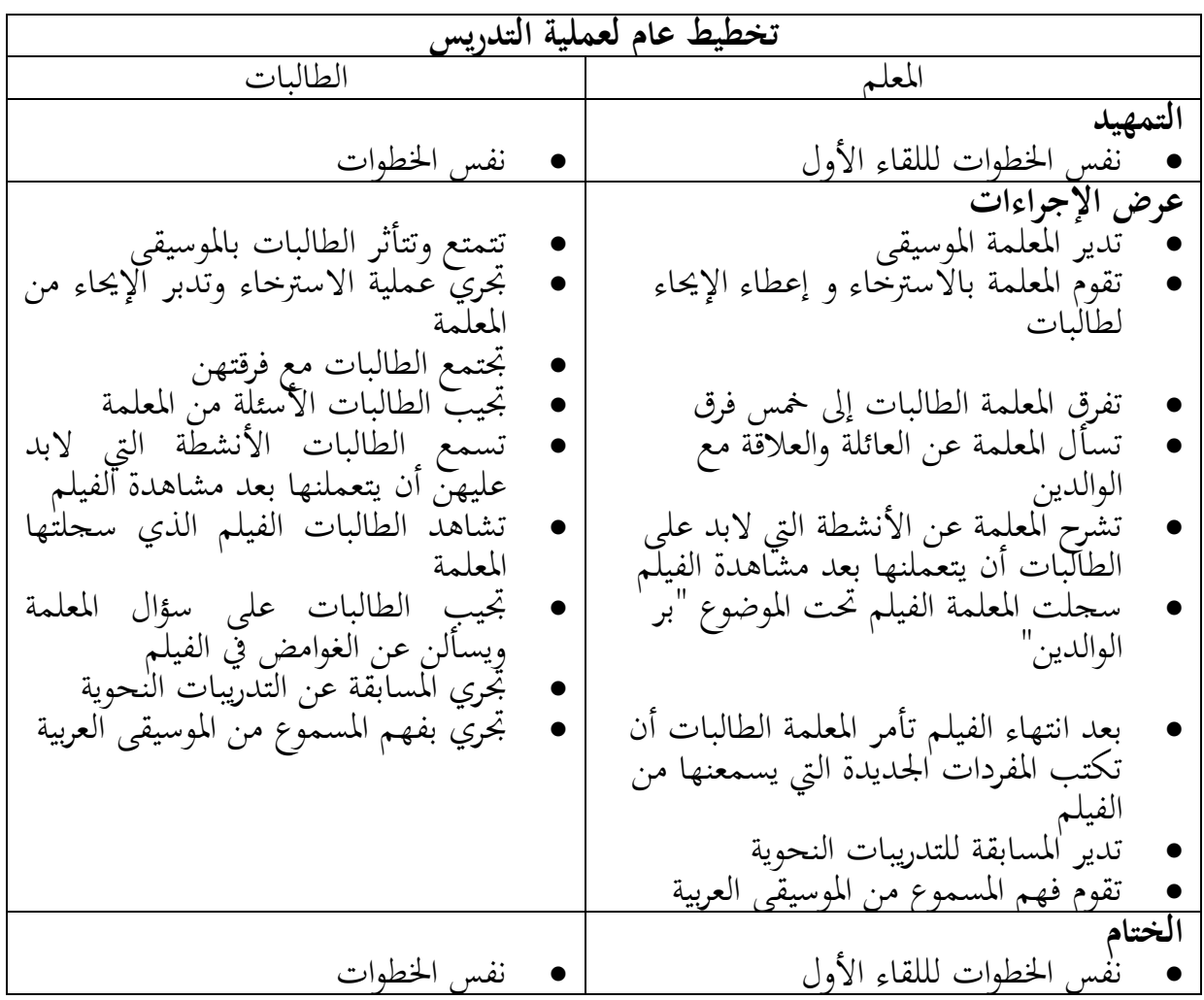


اللقاء الرابع، الموضوع: المقصق

1- الهدف العام : فهم اللغة العربية حين يسمعها الدارس في مواقف الحياة اليومية في حدود ما

درس.

r- - الهدف الخاص: (أ) أن يستخدم الدارس التعبيرات اليومية وعبارات التحية والبحاملة عن الحوار

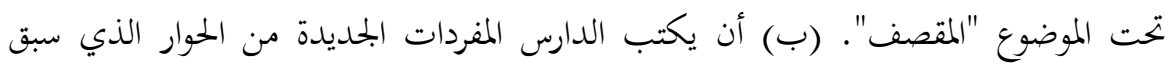

سمعها.

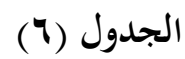

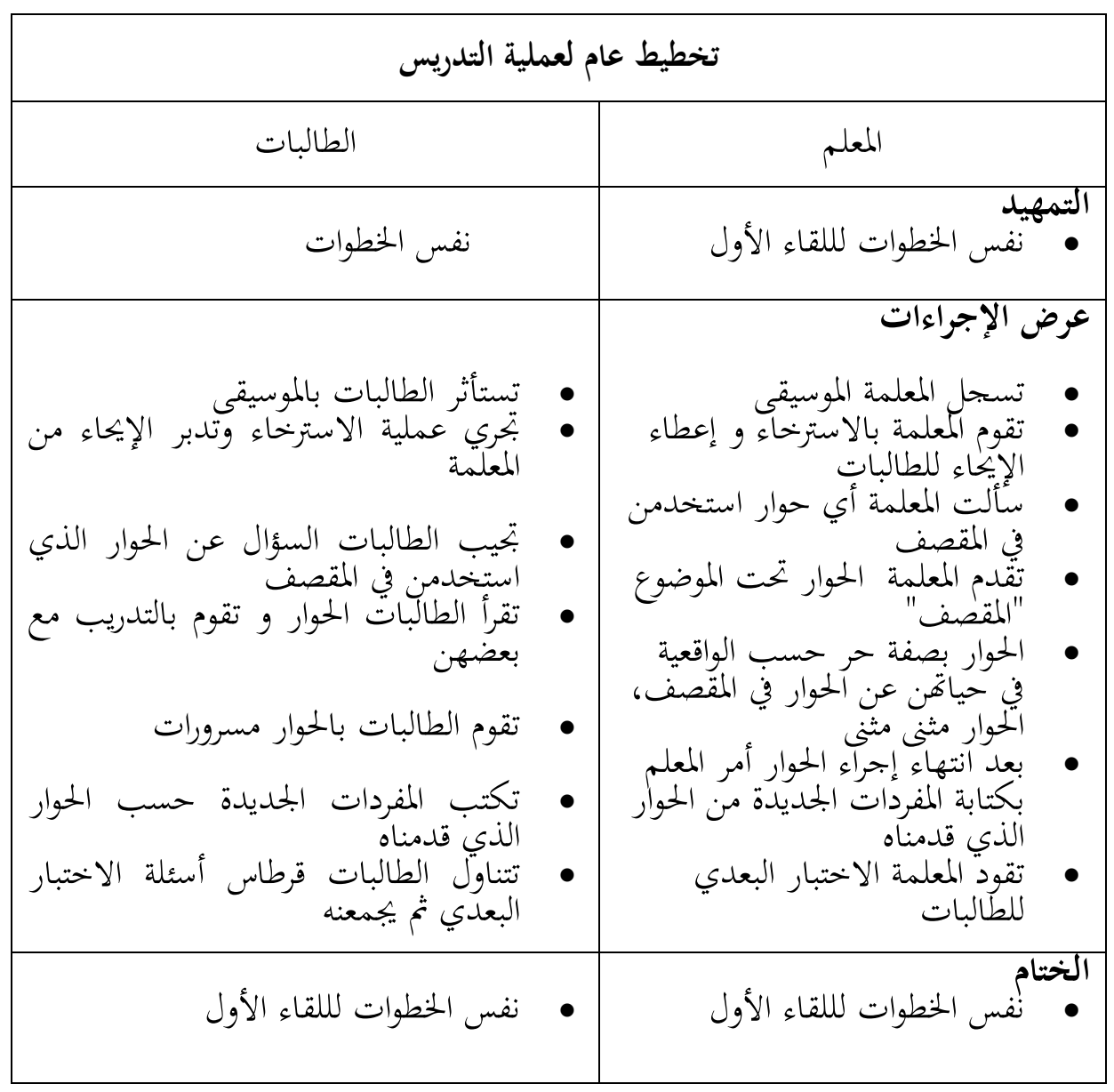




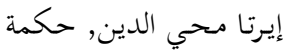

بيانات الاستمارات وتحليلها ومناقشاتها

قُدّمت الاستمارات للطالبات لمعرفة آرائهن عن الطريقة الإيحائية. تتكون الاستمارات من

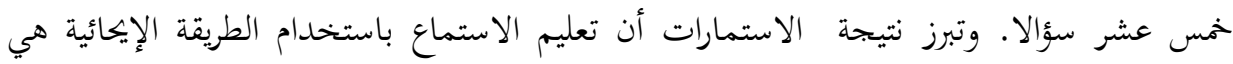

فعالة.

(V) الجدول

نيتجة الاستمارات للمجموعة التجريبية أ (النسائي)

\begin{tabular}{|c|c|c|c|c|c|}
\hline \multicolumn{4}{|c|}{ 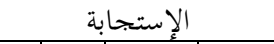 } & \multirow{2}{*}{ التصريحات في الاستبيان } & \multirow{2}{*}{ 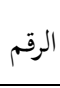 } \\
\hline 1 & r & $r$ & $\varepsilon$ & & \\
\hline & & 1. & ir & مهارة الاستماع مهمة جدا & 1 \\
\hline & 7 & V & 9 & كل طالبة يجب عليها تعلم مهارة الاستماع & r \\
\hline & $r$ & 9 & 11 & النص في تعليم الاستماع نافع جدا & $r$ \\
\hline & & 0 & IV & تعليم الاستماع باستخدام الطريقة الإيهائية مريح & $\varepsilon$ \\
\hline & r & 0 & $1 \varepsilon$ & تعليم الاستماع باستخدام الطريقة الإيجائية أسهل & 0 \\
\hline & 1 & V & $1 \varepsilon$ & تعليم الاستماع باستخدام الطريقة الإيحائية تؤتي بالاطمئنان & 7 \\
\hline & 0 & 11 & 7 & بالطريقة الإيحائية أستطيع أن أبين ما سمعته من النص & $\mathrm{V}$ \\
\hline & r & $1 \cdot$ & 1 . & بالطريقة الإيحائية حصلت على التصور الواضح عن مادة مسموعة & $\wedge$ \\
\hline & r & ir & V & بالطريقة الإيحائية لدي القدرة في إجابة الأسئلة & 9 \\
\hline & tr & $\varepsilon$ & 17 & بالطريقة الإيحائية أحب تعليم اللغة العربية أكثر & 1. \\
\hline & r & 11 & $\Lambda$ & بالطريقة الإيجائية لدي القدرة في كتابة ما سمعته من النص & 11 \\
\hline & tr & $\Lambda$ & ir & بالطريقة الإيحائية أشعر أن التعليم يجري بسرعة & it \\
\hline & r & $\Lambda$ & Ir & المدرسة كأبوي في استخدام الطريقة الإيحائية & 14 \\
\hline & r & 7 & $1 \leq$ & المدرسة كصديقتى في استخدام الطريقة الإيحائية & $1 \varepsilon$ \\
\hline & 1 & $\Lambda$ & 14 & تعامل المدرسة الطالبات معاملة حسنة & 10 \\
\hline
\end{tabular}

هذه نتائج إحصاء الاستمارة وتفسيرها

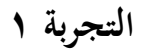

\begin{tabular}{|c|c|c|c|c|c|}
\hline & & Frequency & Percent & Valid Percent & Cumulative Percent \\
\hline Valid & TS & 1 & r & $r$ & r \\
\hline & $\mathrm{RR}$ & $\varepsilon$. & $1 K .1$ & $\mid r .1$ & IT. \\
\hline & s & $1 \pi 1$ & rq. 1 & rq.v & OY.I \\
\hline & SS & 101 & $\varepsilon \vee .9$ & $\varepsilon \vee . q$ & $1 \ldots$ \\
\hline & بحموع & rr. & $1 \ldots$ & $1 \ldots$ & \\
\hline
\end{tabular}




\section{(^) الجدول (ᄉ)}

نتيجة الاستمارات للمجموعة التجريبية ب (السمرقندي)

\begin{tabular}{|c|c|c|c|c|c|}
\hline \multicolumn{4}{|c|}{ 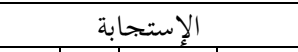 } & \multirow{2}{*}{ التصريهات في الاستمارات } & \multirow{2}{*}{ 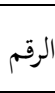 } \\
\hline 1 & r & $r$ & $\varepsilon$ & & \\
\hline & & $\wedge$ & ir & مهارة الاستماع مهمة جدا & 1 \\
\hline & & 14 & 9 & كل طالبة يجب عليها تعلم مهارة الاستماع & r \\
\hline & r & $\wedge$ & 11 & النص في تعليم الاستماع نافع جدا & $r$ \\
\hline & 1 & $\varepsilon$ & IV & تعليم الاستماع باستخدام الطريقة الإيحائية مريحا & $\varepsilon$ \\
\hline & & $1 \cdot$ & $1 \varepsilon$ & تعليم الاستماع باستخدام الطريقة الإيحائية أسهل & ○ \\
\hline & r & 9 & $1 \leq$ & تعليم الاستماع باستخدام الطريقة الإيحائية بتعل بالاطمئنان & 7 \\
\hline & 0 & 9 & 7 & بالطريقة الإيحائية أستطيع أن أبين ما سمعته من النص & $\mathrm{V}$ \\
\hline \multirow[t]{5}{*}{1} & 1 & ir & 1. & بالطريقة الإيمائية حصلت على التصور & $\Lambda$ \\
\hline & r & 10 & $\mathrm{~V}$ & بالطريقة الإيحائية لدي القدرة في إجابة الأسئلة & 9 \\
\hline & r & 9 & 17 & بالطريقة الإيحائية أحب تعليم اللغة العربية أكثر & $1 \cdot$ \\
\hline & $r$ & 14 & $\Lambda$ & بالطريقة الإيحائية لدي القدرة في كتابة ما سمعته من النص & 11 \\
\hline & r & 0 & ir & بالطريقة الإيجائية أشعر أن التعليم يجري بسرعة & Ir \\
\hline \multirow[t]{3}{*}{ r } & r & $1 \cdot$ & ir & المدرس كأبوي في استخدام الطريقة الإيمائية & 14 \\
\hline & r & $\circ$ & $1 \varepsilon$ & المدرس كصديق في استخدام الطريقة الإيحائية & $1 \varepsilon$ \\
\hline & $\varepsilon$ & $\varepsilon$ & 14 & يعامل المدرس الطلبة معاملة حسنة & 10 \\
\hline
\end{tabular}

هذه نتائج إحصاء الاستمارة وتفسيرها

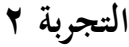

\begin{tabular}{|c|c|c|c|c|c|}
\hline & & Frequency & Percent & Valid Percent & Cumulative Percent \\
\hline Valid & $\begin{array}{l}\text { TS } \\
\text { RR } \\
\text { S } \\
\text { SS } \\
\text { محوع }\end{array}$ & $\begin{array}{c}7 \\
r r \\
14 . \\
191 \\
r 7 .\end{array}$ & $\begin{array}{c}1 . V \\
9 . r \\
r 7.1 \\
0 . .1 \\
1 . .\end{array}$ & $\begin{array}{c}1 . V \\
9 . r \\
r 7.1 \\
0 . .1 \\
1 . .\end{array}$ & $\begin{array}{l}1 . V \\
1 . .1 \\
\leqslant 7.9 \\
1 \ldots\end{array}$ \\
\hline
\end{tabular}

بيانات الاختبار وتحليلها ومناقشتها

\section{(9) الجدول}

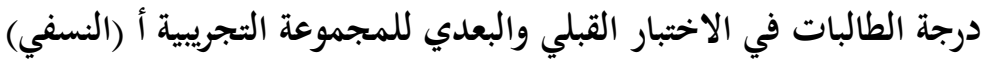

\begin{tabular}{|c|c|c|c|c|c|c|}
\hline البعدي & الاختبار القبلي & الاختبار البعدي & الاختبار القبلي & الاختبار البعدي & القبلي & الطالبات \\
\hline 9. & 7. & $q$. & Vq & Vq & 9. & 1 \\
\hline 19 & 70 & $q 4$ & VI & $\Lambda$. & $V \varepsilon$ & $r$ \\
\hline$\Lambda \mathrm{V}$ & תו & 19 & $V$. & $\Delta r$ & ᄉ. & $r$ \\
\hline
\end{tabular}




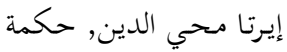

\begin{tabular}{|c|c|c|c|c|c|c|}
\hline$\Lambda$. & 0. & 17 & VA & Vq & N & $\varepsilon$ \\
\hline$q r$ & 70 & $q$ & $\Lambda$. & $\Lambda \wedge$ & NY & 0 \\
\hline 94 & V. & 9. & Nr & $1 \ldots$ & $\lambda r$ & 7 \\
\hline N & 7. & $q r$ & $\Lambda \vee$ & Nr & $\Lambda \varepsilon$ & $V$ \\
\hline 19 & VY & $q r$ & 19 & $1 \ldots$ & N & $\Lambda$ \\
\hline$\Lambda r$ & 7. & $\Lambda \vee$ & VY & $\Lambda$ & $7 \mathrm{~V}$ & 9 \\
\hline 19 & V7 & $1 \ldots$ & 9. & 94 & $7 V$ & 1. \\
\hline 9. & VY & 97 & 19 & $1 \ldots$ & 19 & 11 \\
\hline ᄉᄉ & 70 & $q r$ & 19 & 19 & $q r$ & $1 Y$ \\
\hline 9. & $V$. & 97 & 94 & $1 \ldots$ & $9 \varepsilon$ & $1 \%$ \\
\hline$V Y$ & 0. & $\Lambda$. & 70 & 71 & $\Lambda$. & $1 \varepsilon$ \\
\hline 19 & 79 & 19 & $V_{7}$ & $9 r$ & 91 & 10 \\
\hline 97 & VY & 97 & $\Lambda \varepsilon$ & $9 \leq$ & $9 \varepsilon$ & 17 \\
\hline$q r$ & Vq & $1 \ldots$ & $\Lambda 7$ & $1 \ldots$ & 94 & 18 \\
\hline ᄉr & $V$. & $1 \ldots$ & 19 & $9 \leq$ & 19 & 11 \\
\hline 19 & $V$. & $1 \ldots$ & 9. & $q r$ & Nr & 19 \\
\hline 9. & VT & $9 V$ & 94 & $1 \ldots$ & 94 & $r$. \\
\hline $9 r$ & Vr & $1 \ldots$ & $q 4$ & $1 \ldots$ & 19 & YI \\
\hline 19 & 70 & $\Lambda T$ & $V$. & 人r & Vq & $Y Y$ \\
\hline
\end{tabular}

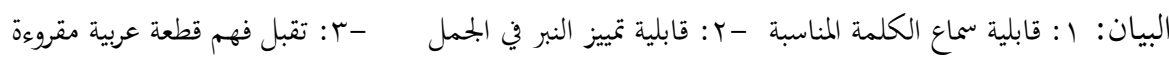

$$
\text { (1.) الجدول }
$$

درجة الطالبات في الاختبار القبلي والبعدي للمجموعة التجريبية ب (السمرقندي)

\begin{tabular}{|c|c|c|c|c|c|c|}
\hline البعدي & الاختبار القبلي & البعدي & القبلي & البعدي & الاختبار القبلي & الرقم \\
\hline 19 & 79 & $\Lambda \varepsilon$ & $v$. & $\Lambda \mu$ & 9. & 1 \\
\hline 9. & V. & Ar & VY & $1 \ldots$ & 90 & $r$ \\
\hline 10 & 70 & 9. & $\mathrm{Vq}$ & $q \pi$ & $\Lambda r$ & $r$ \\
\hline$\vee \wedge$ & 00 & 19 & $V \varepsilon$ & NT & $9 \leqslant$ & $\varepsilon$ \\
\hline 10 & $\Lambda \varepsilon$ & 97 & NT & $1 \ldots$ & 10 & 0 \\
\hline Vo & $V_{7}$ & 91 & ᄉ. & $1 \ldots$ & 9. & 7 \\
\hline 19 & 71 & $9 \leqslant$ & Vq & $1 \ldots$ & 97 & V \\
\hline$q$. & 7. & 9. & NT & $q r$ & 97 & $\Lambda$ \\
\hline 94 & $V$. & 17 & ᄉ. & $1 \ldots$ & 97 & 9 \\
\hline$V$. & 71 & $\Lambda$. & $\vee \wedge$ & $\Lambda \vee$ & 97 & 1. \\
\hline $\mathrm{VA}$ & 70 & $\mathrm{Vq}$ & $\mathrm{Vq}$ & $9 r$ & $\Lambda_{7}$ & 11 \\
\hline 19 & 0. & $\Lambda$. & 71 & $\Lambda_{7}$ & 97 & $1 Y$ \\
\hline 10 & VY & 97 & $\Lambda \vee$ & $9 \mathrm{~V}$ & $1 \ldots$ & Ir \\
\hline ᄉ. & Vo & 91 & ᄉ. & $1 \ldots$ & $1 \ldots$ & $1 \varepsilon$ \\
\hline $9 T$ & vo & 9. & AT & $1 \ldots$ & $q \pi$ & 10 \\
\hline 10 & 71 & 71 & $V$. & Nr & $9 \mathrm{~V}$ & 17 \\
\hline 19 & VT & 9. & $\Lambda \varepsilon$ & $1 \ldots$ & 99 & IV \\
\hline
\end{tabular}




\begin{tabular}{|c|c|c|c|c|c|c|}
\hline$V T$ & Vo & $9 \leqslant$ & $\Delta r$ & $1 \ldots$ & 91 & 11 \\
\hline$\Lambda$. & $V$. & $9 \varepsilon$ & 19 & $1 \ldots$ & 91 & 19 \\
\hline 19 & $V$. & 19 & 19 & $1 \ldots$ & 91 & $r$. \\
\hline 10 & 70 & 97 & 10 & $1 \ldots$ & 97 & YI \\
\hline$\Lambda$. & 71 & 9. & $\mathrm{Vq}$ & $9 r$ & 94 & YY \\
\hline$\Delta r$ & 71 & $\Lambda \varepsilon$ & 10 & $1 \ldots$ & 97 & $r Y$ \\
\hline$q r$ & $V Y$ & $\wedge$. & $\Lambda$. & $9 V$ & 97 & $Y \varepsilon$ \\
\hline
\end{tabular}

البيان: ا: قابلية سماع الكلمة المناسبة - r: قابلية تمييز النبر في الجمل - r: تقبل فهم قطعة عربية مقروءة

\section{الجدول (11)}

درجة الطالبات في الاختبار القبلي والبعدي للمجموعة الضابطة (الصابوني)

\begin{tabular}{|c|c|c|c|c|c|c|}
\hline الاخعدبار & الاخبلي & الاخعديار & الاخبلي & الإختبار & الاختبار & الطالبات \\
\hline$\Lambda$. & $v$. & 90 & $\Lambda$. & $1 \ldots$ & $9 \varepsilon$ & 1 \\
\hline 79 & 79 & 9. & $\Lambda \varepsilon$ & $1 \ldots$ & $\Lambda \mu$ & $r$ \\
\hline 91 & $V$. & 19 & $\mathrm{Vq}$ & $1 \ldots$ & 91 & $r$ \\
\hline$V T$ & $T \varepsilon$ & 9. & 10 & 19 & 90 & $\varepsilon$ \\
\hline$\wedge$. & $V \varepsilon$ & 90 & $\Lambda \varepsilon$ & $1 \ldots$ & 19 & 0 \\
\hline$\wedge \wedge$ & $\pi$ & $\wedge \vee$ & $\wedge 7$ & $\Lambda r$ & $\Lambda V$ & 7 \\
\hline 9. & $\mathrm{Vq}$ & $\Lambda \Lambda$ & 19 & $1 \ldots$ & $9 r$ & $V$ \\
\hline$\Lambda \mathrm{V}$ & $V$. & 90 & 9. & $\Lambda 1$ & 91 & $\Lambda$ \\
\hline$\vee \wedge$ & $\mathrm{VA}$ & 19 & 11 & $1 \ldots$ & $1 \ldots$ & 9 \\
\hline$V$. & $V Y$ & $\Lambda \mathrm{V}$ & $\mathrm{Vq}$ & $9 r$ & $9 \leq$ & 1. \\
\hline TV & 70 & $\mathrm{Vq}$ & $7 \mathrm{~V}$ & Nr & $\Delta r$ & 11 \\
\hline 79 & 71 & $\wedge$. & $V T$ & $\wedge$. & 97 & $1 \%$ \\
\hline $7 \mathrm{~V}$ & TV & 10 & $V 7$ & 19 & 9. & 14 \\
\hline$\wedge$. & VY & $\mathrm{VA}$ & 71 & $9 r$ & 94 & $1 \varepsilon$ \\
\hline 10 & $\Delta r$ & $V$. & 70 & 10 & $\Lambda \varepsilon$ & 10 \\
\hline$V r$ & $\mathrm{VI}$ & $\Delta r$ & $V$. & $V r$ & $V T$ & 17 \\
\hline 19 & 9. & $9 \leqslant$ & 10 & 97 & 97 & 18 \\
\hline$\Lambda$. & $V 7$ & 19 & VI & $\Lambda$. & $7 r$ & 11 \\
\hline$V 7$ & 7. & 9. & $V 7$ & 19 & 94 & 19 \\
\hline$\Lambda \Lambda$ & 79 & 90 & $\Lambda V$ & 10 & $V 7$ & $r$. \\
\hline 91 & $\Lambda V$ & $1 \ldots$ & 91 & $1 \ldots$ & 91 & YI \\
\hline$\Lambda \mathrm{V}$ & Vo & $\Delta r$ & $V$. & Nr & $V V$ & $Y Y$ \\
\hline$\Lambda \varepsilon$ & $V \varepsilon$ & $\wedge \vee$ & $\mathrm{Vq}$ & 19 & 7. & $r r$ \\
\hline
\end{tabular}

البيان: ا: قابلية سماع الكلمة المناسبة - r: قابلية تمييز النبر في الجمل - r: تقبل فهم قطعة عربية مقروءة 


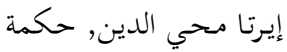

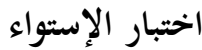

أ- اختبار الإستواء للفصل التجريبي أ (النسفي)

Tests of Normality

\begin{tabular}{|c|c|c|c|c|c|c|c|}
\hline & & \multicolumn{3}{|c|}{ Kolmogorov-Smirnov ${ }^{a}$} & \multicolumn{3}{|c|}{ Shapiro-Wilk } \\
\hline & & Statistic & $\mathrm{df}$ & Sig. & Statistic & Df & Sig. \\
\hline 1 & قياس قابلية سماع الكلمة المناسبة & .208 & 22 & .014 & .908 & 22 & .054 \\
\hline r & قياس قابلية تمييز النبر في الجمل & .161 & 22 & .145 & .905 & 22 & .058 \\
\hline r & قياس تقبل فهم قطعة عربية مقروءة & .269 & 22 & .000 & .846 & 22 & .053 \\
\hline
\end{tabular}

اتضحت من النتائج السابقة بأن الفصل التجريبي أ عادى على مستوى الثقة ه = 0,05.

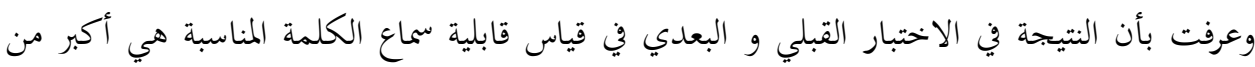

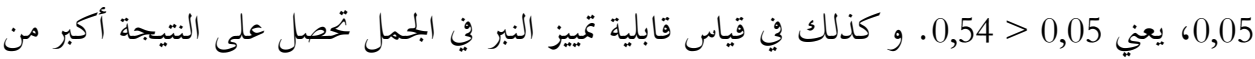

0,05، يعني 0,05 > 0,58. وفي قياس تقبل فهم قطعة عربية مقروءة تحصل عل النتيجة أكبر من 0,05،

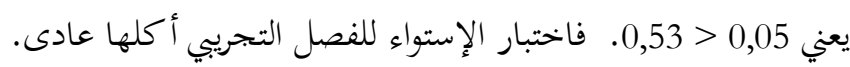

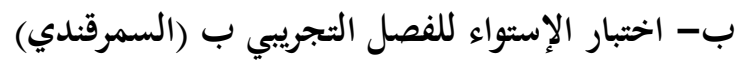

Tests of Normality

\begin{tabular}{|c|c|c|c|c|c|c|c|}
\hline & & \multicolumn{3}{|c|}{ Kolmogorov-Smirnova } & \multicolumn{3}{|c|}{ Shapiro-Wilk } \\
\hline & & Statistic & Df & Sig. & Statistic & Df & Sig. \\
\hline 1 & قياس قابلية سماع الكلمة المناسبة & .253 & 24 & .000 & .803 & 24 & .000 \\
\hline r & قياس قابلية تمييز النبر في الجمل & .181 & 24 & .041 & .922 & 24 & .066 \\
\hline r & قياس تقبل فهم قطعة عربية مقروءة & .174 & 24 & .058 & .945 & 24 & .208 \\
\hline
\end{tabular}

أشارت البيانات المقدمة أعلاه بأن الفصل التجريبي ب عادى على مستوى الثقة م = 0,05.

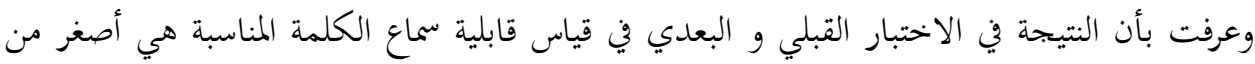

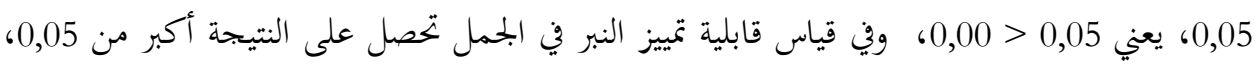

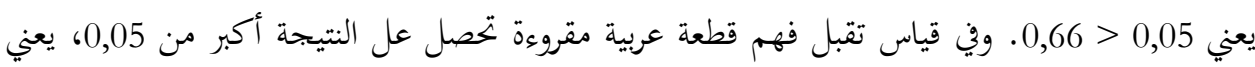


2,08 > 0,05. فاختبار الإستواء للفصل التجربي ب ليس استواء في قياس قابلية على سماع الكلمة المناسبة، وأما النتيجة في اختبارين هي عادى.

ج- اختبار الإستواء للفصل الضابط (الصابوني)

Tests of Normality

\begin{tabular}{|c|c|c|c|c|c|c|c|}
\hline & & \multicolumn{3}{|c|}{ Kolmogorov-Smirnova } & \multicolumn{3}{|c|}{ Shapiro-Wilk } \\
\hline & & Statistic & Df & Sig. & Statistic & Df & Sig. \\
\hline 1 & قياس قابلية سماع الكلمة المناسبة & .190 & 23 & .031 & .894 & 23 & .051 \\
\hline r & قياس قابلية تمييز النبر في الجمل & .152 & 23 & .178 & .955 & 23 & .371 \\
\hline r & قياس تقبل فهم قطعة عربية مقروءة & .117 & 23 & $.200^{*}$ & .957 & 23 & .400 \\
\hline
\end{tabular}

عرفت من البيانات المقدمة أعلاه بأن الفصل الضابط عادى على مستوى الثقة ه = 0,05.

وعرفت بأن النتيجة في الاختبار القبلي و البعدي في قياس قابلية سماع الكلمة المناسبة هي أكبر من

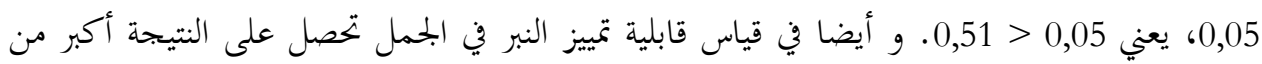
0,05، يعني 3,71 > 0,05 وفي قياس تقبل فهم قطعة عربية مقروءة تحصل عل النتيجة أكبر من 0,05، يعني 0,05 > 4,00. فاختبار الإستواء لفصل الضابط كلها عادى.

اختبار الفرضية

أ- نتيجة اختبار t في الفصل التجريبي أ (النسائي)

Paired Samples Statistics

\begin{tabular}{|c|c|c|c|c|c|}
\hline & & Mean & $\mathrm{N}$ & $\begin{array}{c}\text { Std. } \\
\text { Deviation }\end{array}$ & $\begin{array}{c}\text { Std. Error } \\
\text { Mean }\end{array}$ \\
\hline \multirow{2}{*}{$\begin{array}{l}\text { Pair } \\
1\end{array}$} & قياس قابلية المتعلم على سماع الكلمة المناسبة (قبلى) & 84.86 & 22 & 8.385 & 1.788 \\
\hline & قياس قابلية المتعلم على سماع الكلمة المناسبة (بعدي) & 89.91 & 22 & 9.391 & 2.002 \\
\hline \multirow{2}{*}{$\begin{array}{l}\text { Pair } \\
2\end{array}$} & قياس قابلية الطالبات على تمييز النبر في الجمل (قبلى) & 82.77 & 22 & 8.446 & 1.801 \\
\hline & قياس قابلية الطالبات على تمييز النبر في الجمل (بعدي) & 92.86 & 22 & 5.825 & 1.242 \\
\hline \multirow{2}{*}{$\begin{array}{l}\text { Pair } \\
3\end{array}$} & قياس تقبل فهم قطعة عربية مقروءة بسرعة اعتيادية & 66.77 & 22 & 7.457 & 1.590 \\
\hline & قياس تقبل فهم قطعة مقروءة بسرعة اعتيادية (بعدي) & 87.86 & 22 & 5.148 & 1.098 \\
\hline
\end{tabular}


إيرتا محي الدين, حكمة

Paired Samples Test

\begin{tabular}{|c|c|c|c|c|c|c|c|c|}
\hline & \multicolumn{5}{|c|}{ Paired Differences } & \multirow[b]{3}{*}{$\mathrm{t}$} & \multirow[b]{3}{*}{$\mathrm{df}$} & \multirow[b]{3}{*}{$\begin{array}{c}\text { Sig. } \\
(2- \\
\text { tailed }\end{array}$} \\
\hline & & & & \multicolumn{2}{|c|}{$\begin{array}{c}95 \% \\
\text { Confidence } \\
\text { Interval of the } \\
\text { Difference }\end{array}$} & & & \\
\hline & Mean & $\begin{array}{c}\text { Std. } \\
\text { Deviation }\end{array}$ & $\begin{array}{l}\text { Std. } \\
\text { Error } \\
\text { Mean }\end{array}$ & Lower & Upper & & & \\
\hline 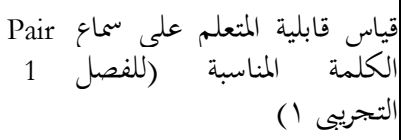 & -5.045 & 9.199 & 1.961 & -9.124 & -.967 & -2.573 & 21 & .018 \\
\hline 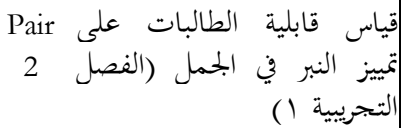 & -10.091 & 4.514 & .962 & -12.092 & -8.090 & -10.486 & 21 & .000 \\
\hline 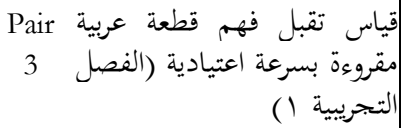 & -21.091 & 4.820 & 1.028 & -23.228 & -18.954 & -20.525 & 21 & .000 \\
\hline
\end{tabular}

من الجدوال السابقة يتضح الأمور التالية: ا- قياس قابلية سماع الكلمة المناسبة

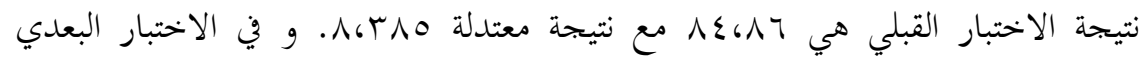
حصلت على النتيجة 19691 مع نتيجة معتدلة 1964.96.

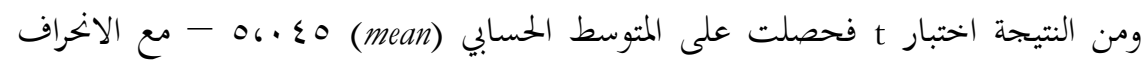

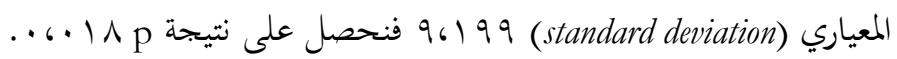

والخلاصة من اختبار t أن لها فرق أو فعالة في قياس قابلية على سماع الكلمة المناسبة بين

$$
\begin{aligned}
& \text { الاختبار القبلي و الاختبار البعدي. } \\
& \text { r- قياس قابلية تمييز النبر في الجمل }
\end{aligned}
$$

نتيجة الاختبار القبلي هي NY،VV مع نتيجة معتدلة 007، ك. و و في الاختبار البعدي

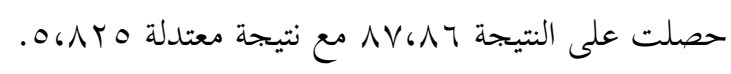

ومن النتيجة اختبار t فحصلت على المتوسط الحسابي 91 .، . 1 - مع الانحراف المعياري

$$
\text { ؛ }
$$


والحلاصة من اختبار t أن لها فرق أو فعالة في قياس قابلية على تمييز النبر في الجمل بين

$$
\begin{aligned}
& \text { الاختبار القبلي و الاختبار البعدي. } \\
& \text { ب- ق قياس تقبل فهم قطعة عربية مقروءة }
\end{aligned}
$$

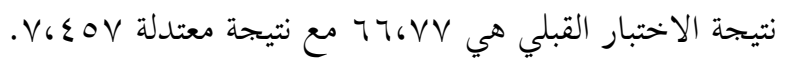

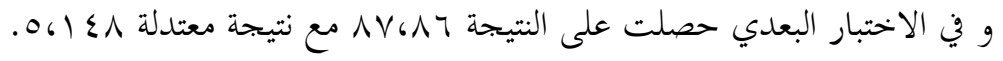

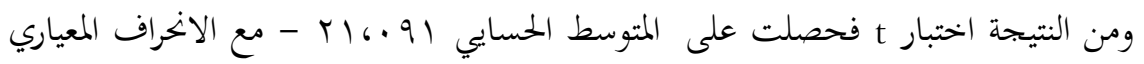

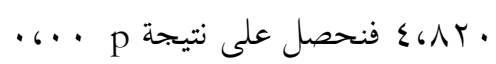

والخلاصة من اختبار t أن لها فرق أو فعالة في قياس تقبل فهم قطعة عربية مقروءة بين

$$
\text { الاختبار القبلي و الاختبار البعدي. }
$$

\begin{tabular}{|c|c|c|c|c|c|}
\hline & & Mean & $\mathrm{N}$ & $\begin{array}{c}\text { Std. } \\
\text { Deviation }\end{array}$ & $\begin{array}{l}\text { Std. Erro } \\
\text { Mean }\end{array}$ \\
\hline & ققبلى) قابلية المتعلم على سماع الكلمة المناسبة & 94.17 & 24 & 4.556 & .930 \\
\hline & قيعدي) قابلية المتعلم على سماع الكلمة المناسبة & 95.29 & 24 & 6.423 & 1.311 \\
\hline \multirow{2}{*}{$\begin{array}{l}\text { Pair } \\
2\end{array}$} & ققياس قابلية الطالبات على تمييز النبر في الجمل & 79.79 & 24 & 5.687 & 1.161 \\
\hline & (بعاسي) قابلية الطالبات على تمييز النبر في الجمل & 88.00 & 24 & 7.138 & 1.457 \\
\hline \multirow{2}{*}{$\begin{array}{l}\text { Pair } \\
3\end{array}$} & قياس تقبل فهم قطعة مقروءة بسرعة اعتيادية & 68.46 & 24 & 7.102 & 1.450 \\
\hline & قياس تقبل فهم قطعة مقروءة بسرعة اعتيادية & 84.42 & 24 & 6.157 & 1.257 \\
\hline
\end{tabular}

$$
\text { ب- نتيجة اختبار t في الفصل التجريبي ب (السمرقندي) }
$$

Paired Samples Statistics

Paired Samples Test

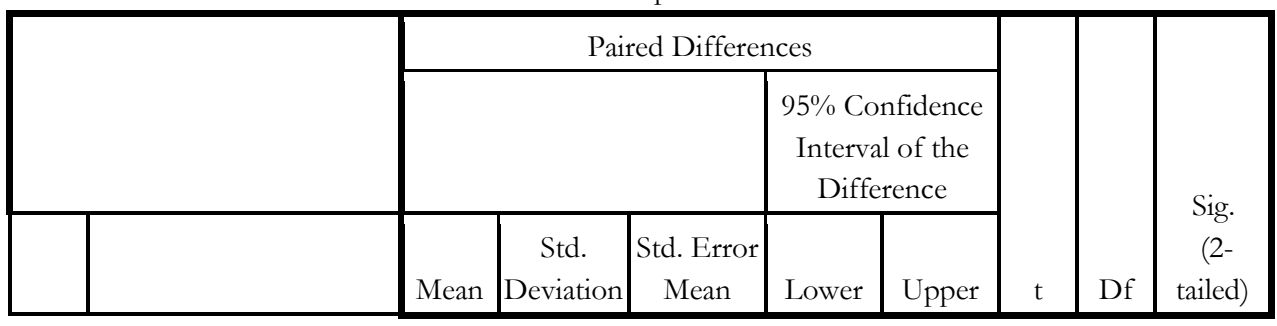


إيرتا محي الدين, حكمة

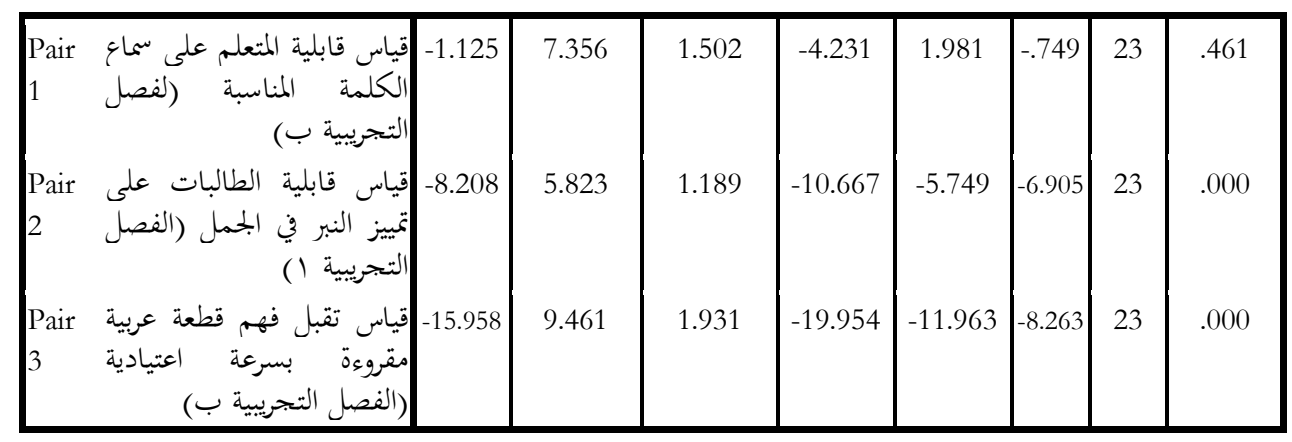

من الجحدوال السابقة تتضح الأمور التالية: ا - قياس قابلية سماع الكلمة المناسبة

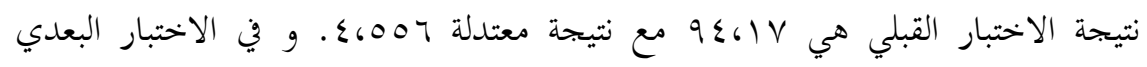

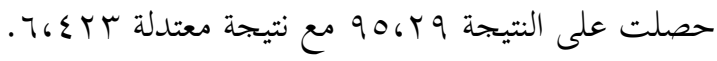

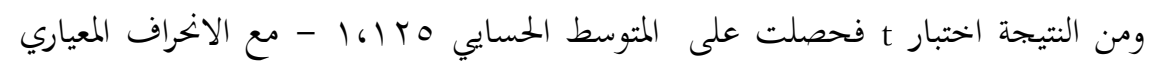

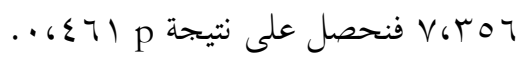
والخلاصة من اختبار t أن ليس هناك فرق أو غير فعالة في قياس قابلية على سماع الكلمة المناسبة بين الاختبار القبلي و الاختبار البعدي. Y

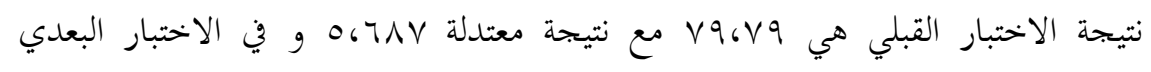

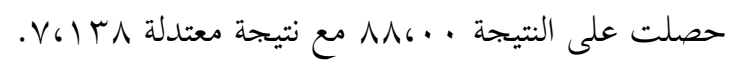

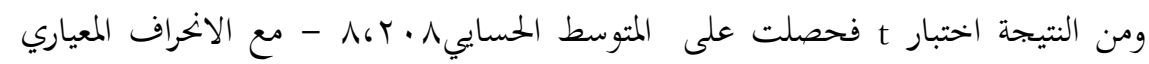

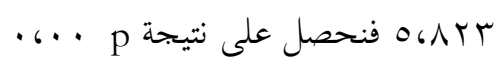
والخلاصة من اختبار t أن لها فرق أو فعالة في قياس قابلية على تمييز النبر في الجمل بين س- قياس تقبل فهم قطعة عربية مقروءة الاختبار القبلي و الاختبار البعدي.

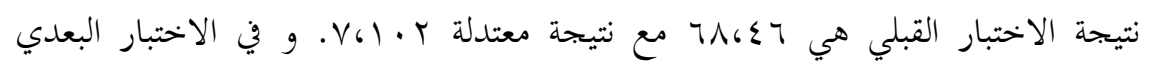

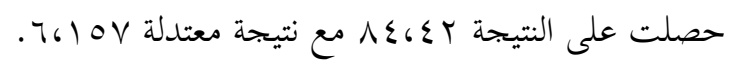


ومن النتيجة اختبار t فحصلت على المتوسط الحسايي106901 - مع الانحراف المعياري

•.. p p p

والخلاصة من اختبار t أن لما فرق أو فعالة في قياس تقبل فهم قطعة عربية مقروءة بين

$$
\text { الاختبار القبلي و الاختبار البعدي. }
$$

ج- نتيجة اختبار t في الفصل الضابط (الصابوني)

Paired Samples Statistics

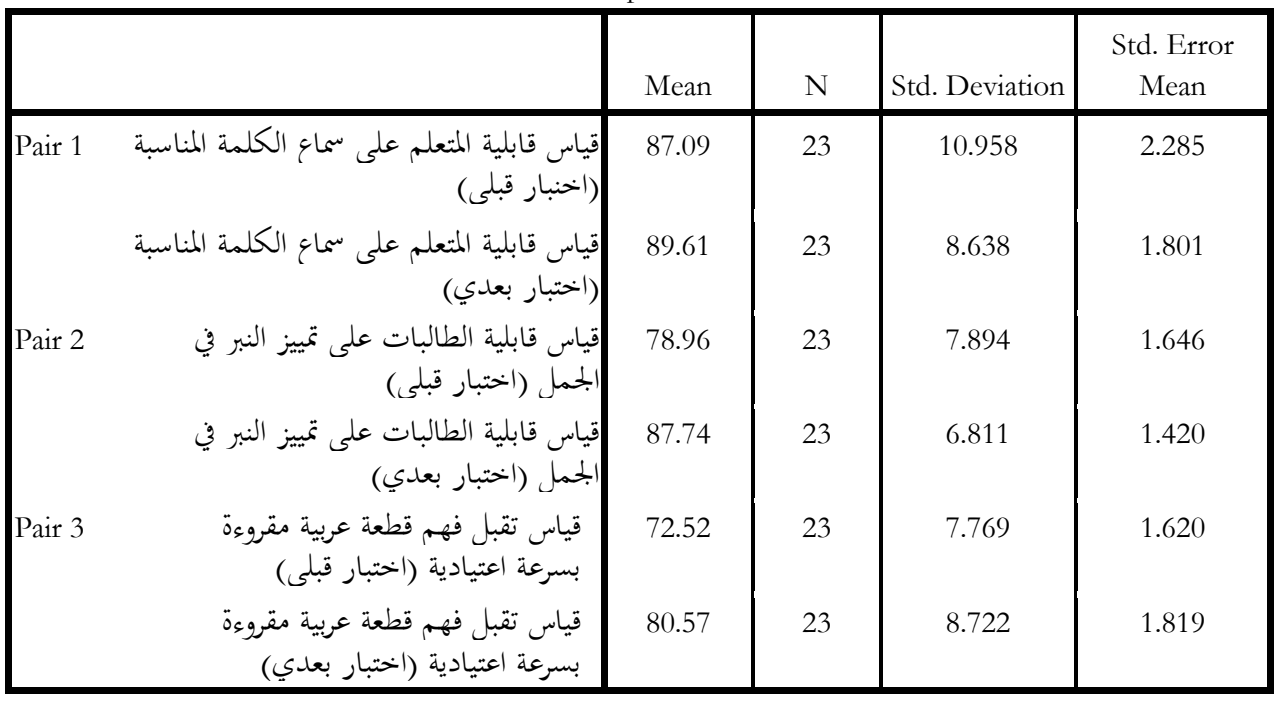

Paired Samples Test

\begin{tabular}{|c|c|c|c|c|c|c|c|c|}
\hline & \multicolumn{5}{|c|}{ Paired Differences } & \multirow[b]{3}{*}{$\mathrm{T}$} & \multirow[b]{3}{*}{ Df } & \multirow[b]{3}{*}{$\begin{array}{l}\text { Sig. } \\
(2- \\
\text { tailed) }\end{array}$} \\
\hline & & & & \multicolumn{2}{|c|}{$\begin{array}{c}95 \% \\
\text { Confidence } \\
\text { Interval of the } \\
\text { Difference }\end{array}$} & & & \\
\hline & Mean & $\mid \begin{array}{c}\text { Std. } \\
\text { Deviation }\end{array}$ & $\begin{array}{l}\text { Std. } \\
\text { Error } \\
\text { Mean }\end{array}$ & Lower & Upper & & & \\
\hline 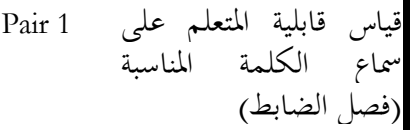 & -2.522 & 9.968 & 2.078 & -6.832 & 1.789 & -1.213 & 22 & .238 \\
\hline
\end{tabular}


إيرتا محي الدين, حكمة

\begin{tabular}{|c|c|c|c|c|c|c|c|c|c|}
\hline Pair 2 & تقييز النبر في الجمابل الطابات عصلى & -8.783 & 4.358 & .909 & -10.667 & -6.898 & -9.664 & 22 & .000 \\
\hline Pair 3 & |عتياس تقبية فقروءة فهم بسرعة & -8.043 & 8.777 & 1.830 & -11.839 & -4.248 & -4.395 & 22 & .000 \\
\hline
\end{tabular}

من الجحوال المقدمة أعلاه يتقدم البحث بالحقائق التالية:

1 - ق قياس قابلية سماع الكلمة المناسبة

نتيجة الاختبار القبلي هي 9.1V6، مع نتيجة معتدلة 901، ـ 1. و و في الاختبار البعدي

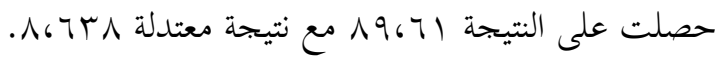

ومن النتيجة اختبار t فحصلت على المتوسط الحسايي roOr r. - مع الانحراف المعياري

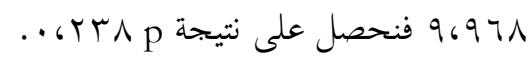

والخلاصة من اختبار t أن ليس هناك فرق أو غير فعالة في قياس قابلية على سماع الكلمة

المناسبة بين الاختبار القبلي و الاختبار البعدي.

r- قياس قابلية تمييز النبر في الجمل

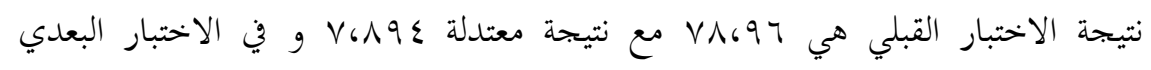

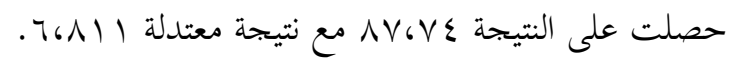

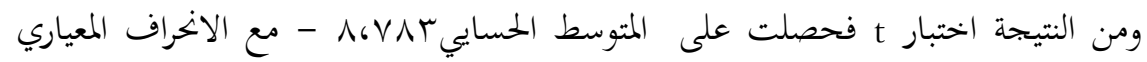

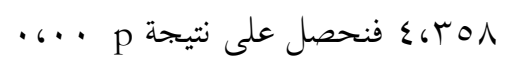

والخلاصة من اختبار t أن لها فرق أو فعالة في قياس قابلية على تمييز النبر في الجمل بين

$$
\text { س- قياس تقبل فهم قطعة عربية مقروءة الاختبار }
$$

نتيجة الاختبار القبلي هي VY60Y مع نتيجة معتدلة V6V79. و في الاختبار البعدي

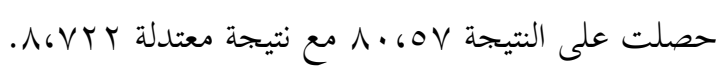

ومن النتيجة اختبار t فحصلت على المتوسط الحسايي؟؟ •16 - مع الانحراف المعياري

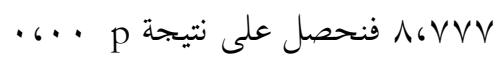


والخلاصة من اختبار t أن لها فرق أو فعالة في قياس تقبل فهم قطعة عربية مقروءة بين

$$
\text { الاختبار القبلي و الاختبار البعدي. }
$$

$$
\begin{aligned}
& \text { أ- نيجة اختبار t بين الفصل التجريبي أ وبين الفصل الضاب } \\
& t=\frac{\bar{x}_{1}-\bar{x}_{2}}{\sqrt{\frac{\left(n_{1}-1\right) s_{1}^{2+}\left(n_{2}-1\right) s_{2}^{2}}{n_{1}+n_{2}-2}\left[\frac{1}{n_{1}}+\frac{1}{n_{2}}\right]}} \\
& t=\frac{90_{-} 85,91}{\sqrt{\frac{(22-1) 154+(23-1) 61,83}{22+23-2}\left[\frac{1}{22}+\frac{1}{23}\right]}} \\
& =\frac{4,09}{\sqrt{\frac{21.154+22.61,83}{43} 0,05+0,04}} \\
& =\frac{4,09}{\sqrt{\frac{3234+1360,07}{43} 0,09}} \\
& =\frac{4,09}{\sqrt{\frac{4594,17}{43} \cdot 0,09}} \\
& =\frac{4,09}{\sqrt{106,84}} 0,09 \\
& =\frac{4,09}{10,34} 0,09 \\
& =0,40 \cdot 0,09 \\
& =0,04
\end{aligned}
$$

ب- نتيجة اختبار t بين الفصل التجريبي ب و الفصل الضابط

$$
\begin{aligned}
t & =\frac{\bar{x}_{1-} \bar{x}_{2}}{\sqrt{\frac{\left(n_{1}-1\right) s_{1}^{2+}\left(n_{2}-1\right) s_{2}^{2}}{n_{1}+n_{2}-2}\left[\frac{1}{n_{1}}+\frac{1}{n_{2}}\right]}} \\
t & =\frac{89,29 \_85,91}{\sqrt{\frac{(24-1) 87,29(23-1) 61,83}{24+23-2}\left[\frac{1}{24}+\frac{1}{23}\right]}} \\
& =\frac{3,38}{\sqrt{\frac{23.87,29+22.61,83}{45} 0,03+0,04}}
\end{aligned}
$$


إيرتا محي الدين, حكمة

$$
\begin{aligned}
& =\frac{3,38}{\sqrt{\frac{2008+1360,07}{45} 0,07}} \\
& =\frac{3,38}{\sqrt{\frac{3367,88}{45} \cdot 0,07}} \\
& =\frac{3,38}{\sqrt{74,84}} 0,07 \\
& =\frac{3,38}{8,65} 0,07 \\
& =0,39 \cdot 0,07 \\
& =0,02
\end{aligned}
$$

dk= n1 + من نتيجة للمجموعة التجريبية أ التي تحصلها فقارنت بنتيجة t table

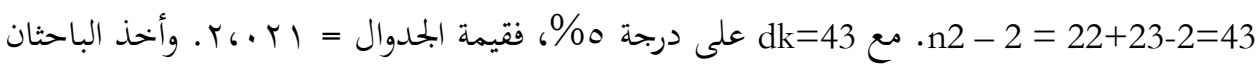

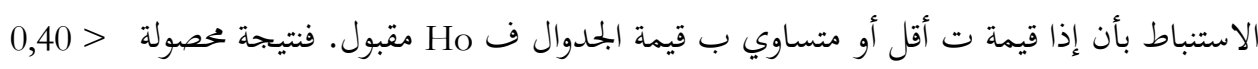
0,021 ف Ho مقبولة و Ha مردود.

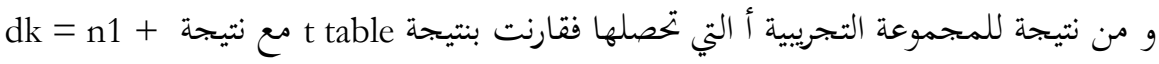

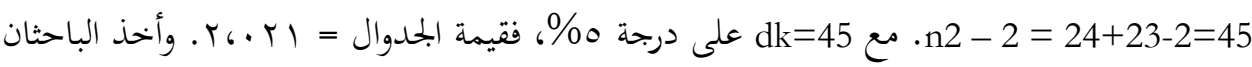

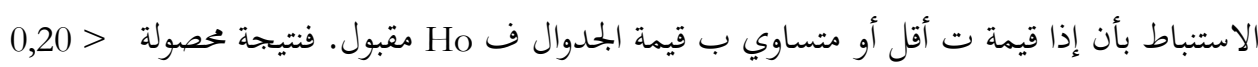
0,021 ف Ho مقبولة و Ha مردود.

انطلاقا من نتائج التي حصل عليها البحث، استنبط الأمور التالية :

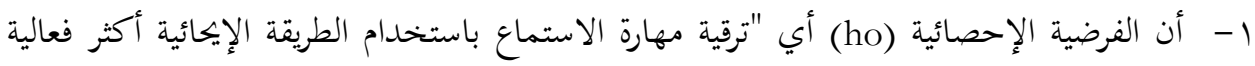

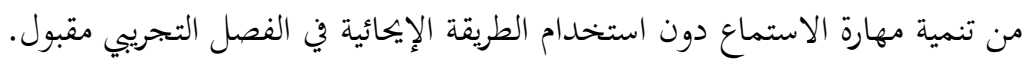

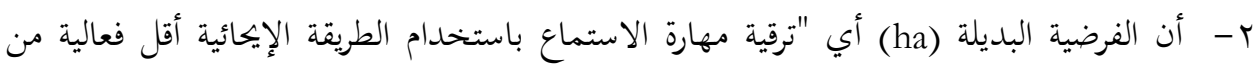
تنمية مهارة الاستماع دون استخدام الطريقة الإيحائية في فصل التجريبي مردود. r- من خلال النتائج السابقة من الواضح أن هذا البحث يشير إلينا بأن استخدام الطريقة الإيحائية يؤثر تأثيرا إيجابيا في تنمية مهارة الاستماع.

بيانات الملاحظة وتحليلها ومناقشتها أ- البيانات من ملاحظة الطالبات عند التعليم 
لاحظ الباحثان الأحوال الطالبات في عملية التعليم واشتراكهن فيها، فوجدت أن بعض

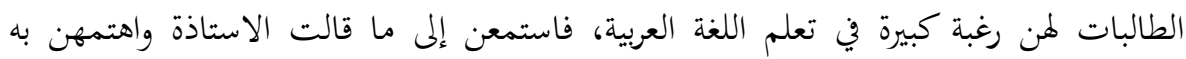

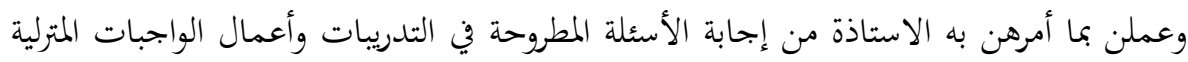

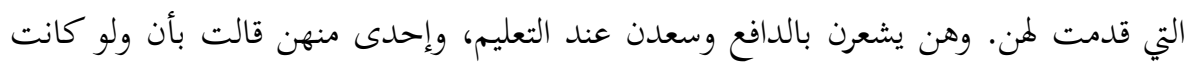

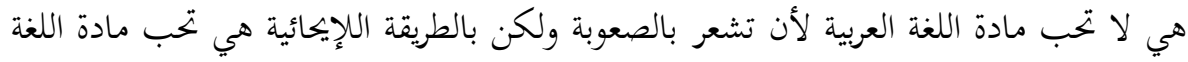
العربية ولا تشعر بالملل وتشعر بالحماسة عند الذهاب إلى المدرسة.

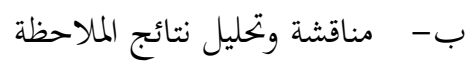
تأكيدا على نتائج الاختبار، عرض الباحثان تحليل نتائج الملاحظة بطريقة الإحصاء

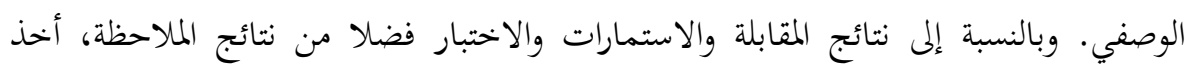

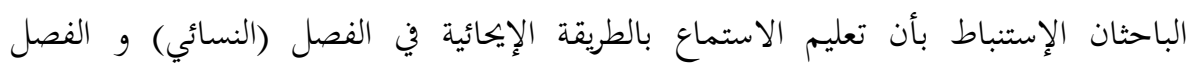

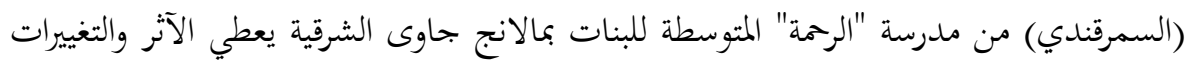

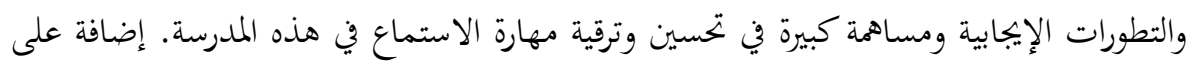

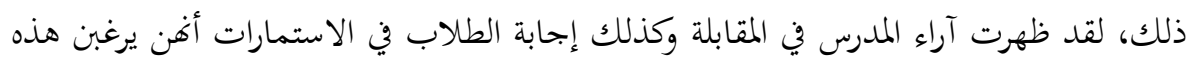

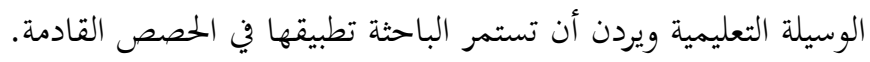

الخاتمة

بعد تحليل البيانات الكمية، فتعرض نتائج البحث أن استخدام الطريقة الإيحائية التي قد أعدها

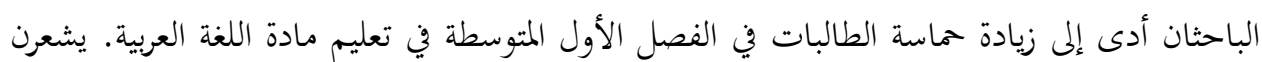

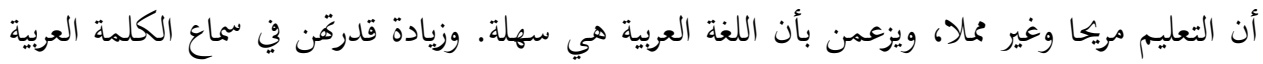

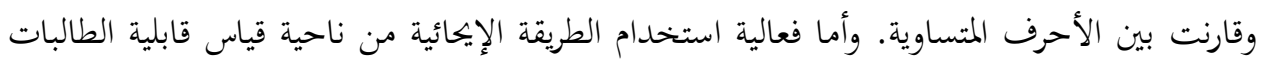

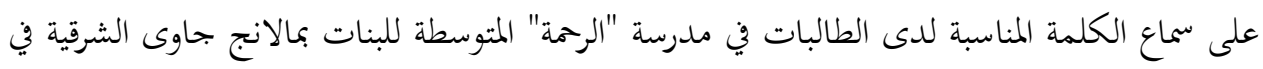

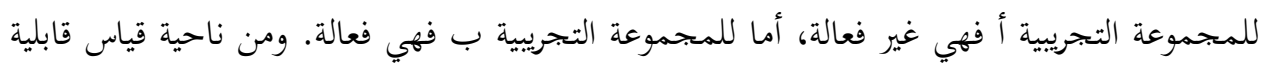

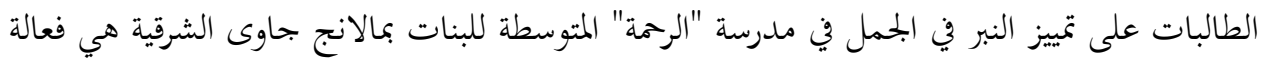
للمجموعة التجريبية أو ب. ومن ناحية قياس تقبل قطعة عربية مقروءة بسرعة اعتيادية لدى الطالبات

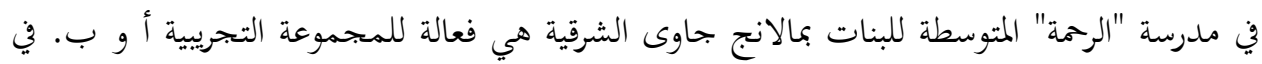
الجملة أن استخدام الطريقة الإيحائية لتعليم الاستماع يجري فعاليا. 


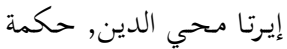

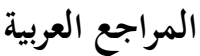

براون، دو جلاس. بر991. أسس تعلم اللغات وتعليمها، ترجمة عبدو الراجحي. بيرت: دار النهضة

العربية.

رتشاردز، جاك. . 199. مذاهب وطرائق في تعليم اللغات، ترجمة الدكتور عبد الرحمن عبد العزيز

العبدان، الرياض: دار العالم الكتب.

شحاته، حسان. rا99 19. تعليم اللغة العربية بين النظرية والتطبيق، الطبعة الثانية. القاهرة: الدار

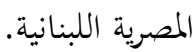

الشنطي، محمد صالح. 999 . المهارات اللغوية، المملكة العببية السعودية: دار الأندلس، الطبعة

الرابعة.

صيني، سعيد إسماعيل. 1999 ـ . قواعدأساسية في البحث العلمي، بيروت: مؤسسة الرسالة.

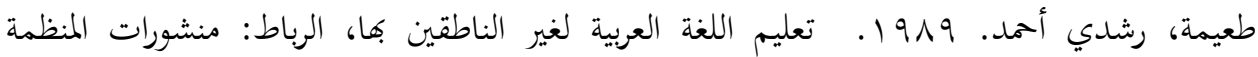
الإسلامية للتربية والعلوم والثقافة.

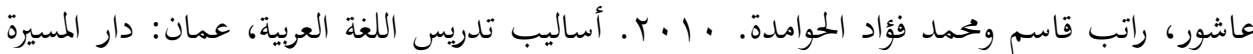
لملنشر والتوزيع، الطبعة الثالثة ،.

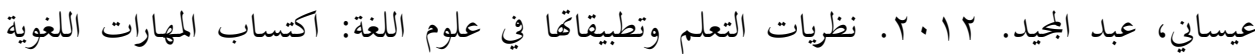
الأساسية، القاهرة: دار الكتاب الحديث، ط لـ المريل

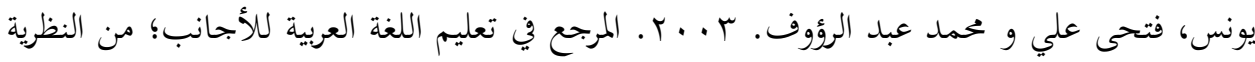
إلى التطبيق، القاهرة: مكتبة وهبة، الطبعة الأولى.

Arsyad, Azhar., (2004). Bahasa Arab dan Metode Pengajarannya. Cetakan II. Yogyakarta: Pustaka Belajar

Fachrurrozi, Aziz dan Erta Mahyudin., (2013). Pembelajaran Bahasa Asing; Metode Tradisional dan Kontemporer, Jakarta: Bania Publishing.

Richard, Jack C. and Theodore S. Rodgers., (1986). Approaches and Methods in Language Teaching; A Description and Analysis. London: Cambridge University Press, Third Printing.

Huda, Nuril., (1999). Language Learning and Teaching Issues and Trends. Malang: IKIP Publisher.

Machmudah, Umi dan Abdul Wahab Rosyidi., (2008). Active Learning dalam Pembelajaran Bahasa Arab, Malang: UIN Maliki Press.

Botha, Ludolph. An Analysis of SALT in Practice. Per Linguam vol. 1 no. I 1985. http://perlinguam.journals.ac.za 
Sigrid Gassner-Robert. Some Personal Observation of SALT, Suggestopedia and Accelerative Learning Methods in Japan and Europe. Per Linguam vol. 2 no. 11986 http://perlinguam.journals.ac.za

Odendaal, M.S. Raising Achievement Levels by Means of Suggestopedia. http://perlinguam.journals.ac.za 